\title{
A breakthrough on Amanita phalloides poisoning: an effective antidotal effect by polymyxin $B$
}

\author{
Juliana Garcia ${ }^{1}$ - Vera Marisa Costa ${ }^{1} \cdot$ Alexandra T. P. Carvalho $^{2}$. \\ Ricardo Silvestre $^{3,4} \cdot$ José Alberto Duarte $^{5}$ Daniel F. A. R. Dourado ${ }^{2}$ \\ Marcelo D. Arbo ${ }^{1} \cdot$ Teresa Baltazar $^{1} \cdot$ Ricardo Jorge Dinis-Oliveira $^{1,6,7}$. \\ Paula Baptista $^{8} \cdot$ Maria de Lourdes Bastos $^{1} \cdot$ Félix Carvalho $^{1}$
}

Received: 23 July 2015 / Accepted: 11 August 2015 / Published online: 18 September 2015

(C) Springer-Verlag Berlin Heidelberg 2015

\begin{abstract}
Amanita phalloides is responsible for more than $90 \%$ of mushroom-related fatalities, and no effective antidote is available. $\alpha$-Amanitin, the main toxin of $A$. phalloides, inhibits RNA polymerase II (RNAP II), causing hepatic and kidney failure. In silico studies included docking and molecular dynamics simulation coupled to molecular mechanics with generalized Born and surface area method energy decomposition on RNAP II. They were performed with a clinical drug that shares chemical similarities to $\alpha$-amanitin, polymyxin $B$. The results show that polymyxin $B$ potentially binds to RNAP II in the same interface of $\alpha$-amanitin, preventing the toxin from binding to RNAP II. In vivo, the inhibition of the mRNA transcripts elicited by $\alpha$-amanitin was efficiently reverted by polymyxin $B$ in the kidneys. Moreover, polymyxin B significantly decreased the hepatic and renal $\alpha$-amanitin-induced injury as seen by the histology and hepatic aminotransferases plasma data. In the survival assay, all animals exposed to $\alpha$-amanitin died within 5 days, whereas $50 \%$ survived up to 30 days when polymyxin B was administered 4,8 , and $12 \mathrm{~h}$ post- $\alpha$-amanitin.
\end{abstract}

Juliana Garcia

garciaju1987@gmail.com

Félix Carvalho

felixdc@ff.up.pt

1 UCIBIO/REQUIMTE-Laboratory of Toxicology, Department of Biological Sciences, Faculty of Pharmacy, University of Porto, Rua José Viterbo Ferreira no 228, 4050-313 Porto, Portugal

2 Department of Cell and Molecular Biology, Computational and Systems Biology, Biomedical Center, Uppsala University, Box 596, 75124 Uppsala, Sweden

3 School of Health Sciences, Life and Health Sciences Research Institute (ICVS), University of Minho, Braga, Portugal
Moreover, a single dose of polymyxin B administered concomitantly with $\alpha$-amanitin was able to guarantee $100 \%$ survival. Polymyxin B protects RNAP II from inactivation leading to an effective prevention of organ damage and increasing survival in $\alpha$-amanitin-treated animals. The present use of clinically relevant concentrations of an already human-use-approved drug prompts the use of polymyxin $\mathrm{B}$ as an antidote for A. phalloides poisoning in humans.

Keywords $\alpha$-Amanitin $\cdot$ RNA polymerase II $\cdot$ Polymyxin B $\cdot$ Liver $\cdot$ Kidney

\section{Introduction}

The gathering and consumption of wild mushrooms has increased during recent years due to their delicate flavors and textures as well as their attributed high nutritional value (Cheung 2010). Despite warnings, edible and toxic mushrooms such as Amanita phalloides are frequently misidentified

4 ICVS/3B's-PT Government Associate Laboratory, Braga, Guimarães, Portugal

5 Faculty of Sport, CIAFEL, University of Porto, Porto, Portugal

6 Department of Legal Medicine and Forensic Sciences, Faculty of Medicine, University of Porto, Porto, Portugal

7 Department of Sciences, IINFACTS-Institute of Research and Advanced Training in Health Sciences and Technologies, Advanced Institute of Health Sciences-North (ISCS-N), CESPU, CRL, Gandra, Portugal

$8 \mathrm{CIMO} / \mathrm{School}$ of Agriculture, Polytechnic Institute of Bragança, Campus de Santa Apolónia Apartado 1172, 5301-854 Bragança, Portugal 
by mushroom collectors. This species is responsible for more than $90 \%$ of the fatalities caused by mushroom poisoning worldwide (Vetter 1998). The high lethality of A. phalloides poisoning relies on the presence of powerful toxins such as cyclic octapeptides. These cyclic octapeptides are known as amatoxins, and $\alpha$-amanitin is mainly responsible for the severe liver and kidney injury observed after A. phalloides poisoning. It is well established that $\alpha$-amanitin inhibits RNA polymerase II (RNAP II), thereby interfering with the transcription process (Wieland 1983). However, other toxic mechanisms have been suggested, namely oxidative stress, which may play a critical role (Leist et al. 1997; Zheleva 2013; Zheleva et al. 2007). In addition, $\alpha$-amanitin may also act synergically with endogenous cytokines (e.g., tumor necrosis factor- $\alpha$ ) to promote apoptosis (Leist et al. 1997).

Unfortunately, so far, no consensual antidote for mushroom poisonings has been found, and therefore, amatoxin poisoning is generally associated with a poor outcome, mainly due to liver or kidney failure. Several treatments have been used after human intoxications with A. phalloides, including hormones (e.g., insulin, growth hormone, and glucagon), steroids, vitamin $\mathrm{C}$, vitamin $\mathrm{E}$, cimetidine, $\alpha$-lipoic acid, antibiotics (benzylpenicillin, ceftazidime), $\mathrm{N}$-acetylcysteine, and silybin. Of the previous, only benzylpenicillin, ceftazidime, $\mathrm{N}$-acetylcysteine, and silybin proved to have some degree of therapeutic efficacy, though the death rate remains extremely high (Poucheret et al. 2010). The survival of individuals depends largely on the severity of liver damage, the rate of hepatic regeneration, and the management of complications that may develop during the intoxication treatment course (Koda-Kimble et al. 2012). Liver transplantation is considered a last resort; however, it remains the cornerstone of treatment in patients with fulminant hepatic failure (Broussard et al. 2001; Pinson et al. 1990).

Considering the main toxicity mechanism of amatoxins (i.e., the inhibition of RNAP II activity), the ideal therapeutic approach against $A$. phalloides intoxications would be to displace and/or compete with the amatoxins binding to RNAP II without impairing its normal transcription activity. Therefore, in the present study, we aimed to identify an effective antidote for Amanita mushroom poisonings. An innovative in silico and in vivo approach based on the binding of $\alpha$-amanitin to RNAP II and the screening of clinical drugs that show bioisosterism with amatoxins are proposed. This bioisosterism was tested in in silico models to assess a putative competition and displacement from amatoxins binding site with RNAP II. After in silico studies, one of the most promising candidates, polymyxin B was chosen to proceed with in vivo testing, mainly focusing on the target organs of $\alpha$-amanitin toxicity, kidney and liver. Several parameters were evaluated, namely the survival rate, histological damage, protein carbonylation, NF-kB nuclear activation, total RNA, and specific mRNA quantification, in order to validate the effectiveness of polymyxin B in protecting mice against $\alpha$-amanitin poisoning.

\section{Materials and methods}

\section{In silico study}

\section{Molecular docking on RNAP II}

Molecular docking plays an important role in the rational design drugs and is helpful in elucidating key features of ligand/receptor interactions. This in silico method allows predicting the preferred orientation of putative antidotes when bound to RNAP II, forming a complex with overall minimum energy. Molecular docking studies were performed on polymyxin B according to our previous reported data (Garcia et al. 2014). The crystal structure of RNAP II complexed with $\alpha$-amanitin (Protein Data Bank entry 3CQZ and 2VUM) was used to obtain the starting structures for the molecular docking (Bushnell et al. 2002), and only subunits Rpb1 and Rpb2 were used. The optimized Rpb1 and Rpb2 subunits were docked with polymyxin $\mathrm{B}$. The docking procedure was made with the AutoDock 4 program (Morris et al. 2009; Mowry et al. 2013). This automated docking program uses a grid-based method for energy calculation of the flexible ligand in complex with a rigid protein. The program performs several runs in each docking experiment. Each run provides one predicted binding mode. The Lamarckian genetic algorithm (LGA) was used in all docking calculations. The $48 \times 44 \times 44$ grid pointed along the $\mathrm{x}, \mathrm{y}$, and $\mathrm{z}$ axes was centered on the $\alpha$-amanitin, which was large enough to cover all possible rotations of the polymyxin $\mathrm{B}$. The distance between two connecting grid points was 0.375 $\AA$. The docking process was performed in 250 LGA runs. The population was 150 , the maximum number of generations was 27,000 and the maximum number of energy evaluations was $2.5 \times 10^{6}$. After complete execution of AutoDock, ten conformations of polymyxin B in complex with the receptor were obtained, which were finally ranked on the basis of binding energy. After analysis, the best docking solution was chosen as starting structure for the subsequent minimization and molecular dynamics simulations.

\section{Optimization of polymyxin B}

The structure of polymyxin B was constructed and optimized in Gaussian at the HF/6-31G* level of theory. Two optimizations were performed: in vacuum and in the condensed phase. The partial charges were calculated resorting to the RESP method. 


\section{Molecular dynamic (MD) simulations}

The enzyme was first neutralized by adding $\mathrm{Na}^{+}$ions and solvated in a cubic box of TIP3P water molecules, such that there were at least $10.0 \AA$ of water between the surface of the protein and the edge of the simulation box. The initial geometry optimization of the enzyme was minimized in two stages. In the first stage, only the hydrogen and water atoms were minimized; in the second stage, the entire system was minimized. The parameters of the chosen models were validated with MD simulations in explicit solvent. The MD was performed with ff99SB force field and the general AMBER force field (GAFF) (Case et al. 2005). An initial minimization was performed followed by an equilibration of 500 ps. The equilibration was performed in a NVT ensemble using Langevin dynamics with small restraints on the protein $(100 \mathrm{kcal} / \mathrm{mol})$. Then, $10 \mathrm{~ns}$ of production simulation was performed. This represented a substantial computational effort, since each system is composed of $\approx 44,000$ atoms containing protein, deoxyribonucleic acid (DNA), and ribonucleic acid (RNA). Temperature was maintained at $300 \mathrm{~K}$ in the NPT ensemble using Langevin dynamics with a collision frequency of $1.0 \mathrm{ps}^{-1}$. The time step was set to $2 \mathrm{fs}$. The trajectories were saved every 500 steps for analysis. Constant pressure periodic boundary was used with an average pressure of $1 \mathrm{~atm}$. Isotropic position scaling was used to maintain the pressure with a relaxation time of $2 \mathrm{ps}$. SHAKE constraints were applied to all bonds involving hydrogen atoms. The particle mesh Ewald (PME) method (Essmann et al. 1995) was used to calculate electrostatic interactions with a cutoff distance of $8.0 \AA$.

\section{Calculation of the binding energy}

Molecular mechanics with generalized Born and surface area solvation (MM-GBSA) was applied to compute the binding energy between the RNAP II/polymyxin B complex and to decompose the interaction energies on a per residue basis by considering molecular mechanics energies and solvation energies (Kollman et al. 2000). The energy decomposition was performed for gas-phase energies, desolvation free energies calculated by GB model (Onufriev et al. 2000), and nonpolar contributions to desolvation using the linear combinations of pairwise overlaps (LCPO) method (Weiser et al. 1999).

\section{Experimental studies}

\section{Chemical and drugs}

$\alpha$-Amanitin, polymyxin B, 1-octanesulfonic acid sodium salt, 2,4-dinitrophenylhydrazine, TRIzol, and RNAlater were purchased from Sigma-Aldrich (St. Louis, Missouri, USA). Methanol and xylene were obtained from Fisher
Scientific (Waltham, Massachusetts, USA). Sodium chloride, potassium chloride, sodium hydrogen phosphate, potassium dihydrogen phosphate, perchloric acid, Histosec paraffin pastilles, magnesium chloride, sodium hydroxide, ethylenediaminetetraacetic acid (EDTA), and disodium phosphate were purchased from Merck (Darmstadt, Germany). Eosin $1 \%$ aqueous was obtained from Biostain (Traralgon, Australia) and Harris hematoxylin from Harris Surgipath (Richmond, Illinois, USA). Water was purified with a Milli-Q Plus ultrapure water purification system (Millipore, Bedford, Massachusetts, USA). Bio-Rad DC protein assay kit, Clarity ${ }^{\mathrm{TM}}$ Western ECL substrate, iScript cDNA Synthesis Kit, and SYBR Green PCR Master Mix were purchased from Bio-Rad Laboratories (Hercules, California, USA). Horseradish peroxidase-conjugated antirabbit antibody, ECL chemiluminescence reagents, and $0.45 \mu \mathrm{m}$ Amersham Protran nitrocellulose blotting membrane were purchased from GE Healthcare Bio-Science (Pittsburgh, Pennsylvania, USA). Dinitropenhyl-KLH rabbit IgG antibody was purchased from Invitrogen/Life Technologies (Grand Island, New York, USA). NF-кB p50 rabbit polyclonal IgG and goat anti-rabbit IgG $\mathrm{F}(\mathrm{ab}$ ')2 AP conjugated were purchased from Santa Cruz Biotechnology (Heidelberg, Germany). All primers were purified through high-pressure liquid chromatography and purchased from STAB Vida (Caparica, Lisboa, Portugal). The kit for DNase digestion step and the ultrapure water was obtained from Qiagen (Carnaxide, Portugal).

\section{Animals}

Male CD-1 mice (20-30 g) were purchased from Harlan (Udine, Italy) and kept in the vivarium of Faculty of Sports, University of Porto. Room temperature was maintained at $22 \pm 2{ }^{\circ} \mathrm{C}$, relative humidity at $60 \pm 10 \%$, and a 12-h light/ dark cycle. Water and standard rodent chow 4RF21 GLP certificate diet (Mucedola, 113 Settimo Milanese, Italy) were provided ad libitum. All procedures were carried out to provide appropriate animal care, minimizing their suffering. Housing and experimental treatment of the animals were in accordance with the guidelines defined by the European Council Directive (2010/63/EU) transposed into Portuguese law (Decreto-Lei n.o 113/2013, de 7 de Agosto). Moreover, the experiments were performed with the approval of the Ethical Committee of the Faculty of Pharmacy (protocol number 10/06/2013), University of Porto. Animals were acclimated for 5 days before starting the experiments.

\section{In vivo study design}

The murine model has been used as a reliable model for $\alpha$-amanitin poisoning (Schneider et al. 1987, 1992; Tong et al. 2007; Yamaura et al. 1986; Zhao et al. 2006), with 
similar hepatic toxic responses as seen in humans after amatoxins administration (Tong et al. 2007). In this model, the intraperitoneal (i.p.) administration ensures the bioavailability of $\alpha$-amanitin and it has been the preferred route used in previous studies in mice regarding the search for antidotes against amatoxin poisoning (Schneider et al. 1987, 1992; Tong et al. 2007). In the present work, two in vivo studies were performed to evaluate the putative effectiveness of polymyxin $B$ against $\alpha$-amanitin toxicity: a short-term study (24 h) and a survival study (30 days). $\alpha$-Amanitin and polymyxin B were always dissolved in $0.9 \%$ saline solution. In both studies, all $\alpha$-amanitin-exposed animals received an i.p. dose of $0.33 \mathrm{mg} / \mathrm{kg}$. This dose was chosen since it was previously reported to be the lethal dose $\left(\mathrm{LD}_{50}\right)$ of $\alpha$-amanitin in mice (Wieland and Faulstich 1978) and it has been used in several studies aiming to test antidotes efficacy after amatoxin poisoning (Schneider et al. 1987, 1992; Tong et al. 2007; Vogel et al. 1984).

\section{Short-term study}

Our work started with a short-term ( $24 \mathrm{~h}$ ) study to evaluate the effectiveness of polymyxin B in protecting liver and kidney against the toxicity of $\alpha$-amanitin. In order to create a real scenario of intoxication, since intoxicated people only arrive to emergency rooms hours or even days after mushrooms ingestion, polymyxin $\mathrm{B}$ was only administered to animals $4 \mathrm{~h}$ post- $\alpha$-amanitin administration. This 4 -h delay in the administration was also used in several studies that aimed testing the efficacy of other antidotal therapies in mice models (Schneider et al. 1992; Tong et al. 2007). Three consecutive doses of polymyxin B $(2.5 \mathrm{mg} / \mathrm{kg})$ with 4 -h interval between each dosage were given to animals. According to the allometric scaling standardly used (Beck et al. 2014), the three doses of $2.5 \mathrm{mg} / \mathrm{kg}$ of polymyxin B in mice sum up to approximately $1 \mathrm{mg} / \mathrm{kg}$ in a $70-\mathrm{kg}$ human. The current recommended dose of intravenous polymyxin $\mathrm{B}$ for patients with normal renal function is $1.5-2.5 \mathrm{mg} / \mathrm{kg} / \mathrm{day}$ in two doses administered as 1-h infusions (Zavascki et al. 2007). Moreover, the three polymyxin B administrations at different time-points $(4,8$, and $12 \mathrm{~h})$ after $\alpha$-amanitin injection are based on a previous pharmacokinetic study in mice with polymyxin $\mathrm{B}$, in which polymyxin $\mathrm{B}(3 \mathrm{mg} / \mathrm{kg})$ is nondetectable in the serum at $4 \mathrm{~h}$ post-administration (He et al. 2013).

Animals were randomly divided into four groups that were treated as follows: (1) control group, animals subjected to four $0.9 \%$ saline solution i.p. administrations $(0,4,8$, and $12 \mathrm{~h})$; (2) $\alpha$-amanitin group (Ama), animals exposed to one dose of $\alpha$-amanitin $(0.33 \mathrm{mg} / \mathrm{kg}$ i.p.) followed by three $0.9 \%$ saline solution i.p. administrations at different time-points $(4,8$, and $12 \mathrm{~h})$ post- $\alpha$-amanitin administration; (3) polymyxin B group (Pol), animals exposed to a $0.9 \%$ saline solution followed by three
$2.5 \mathrm{mg} / \mathrm{kg}$ i.p. administrations of polymyxin B at different time-points (4, 8, and $12 \mathrm{~h}$ ); and (4) $\alpha$-amanitin plus polymyxin B (Ama $+\mathrm{Pol})$, animals exposed to one dose of $\alpha$-amanitin $(0.33 \mathrm{mg} / \mathrm{kg}$ i.p.) followed by three $2.5 \mathrm{mg} / \mathrm{kg}$ i.p. administrations of polymyxin $B$ at different time-points $(4,8$, and $12 \mathrm{~h})$. Twenty-four hours after $\alpha$-amanitin administration, all animals were anesthetized with isoflurane and killed by exsanguination. The blood, liver, and kidney were collected for further analysis.

\section{Survival rate study}

Following the promising in silico and short-term in vivo studies, the next step was to perform a long-term in vivo study, to evaluate survival rate and animals welfare of animals intoxicated with $\alpha$-amanitin and treated with polymyxin $B$. In the $\alpha$-amanitin group, animal suffering was expected; thus, we reduced the number of animals to the minimum. Twenty animals were randomly divided into five groups that were treated as follows: (1) control group, animals treated with $0.9 \%$ saline solution i.p.; (2) $\alpha$-amanitin group (Ama), animals exposed to one dose of $\alpha$-amanitin $(0.33 \mathrm{mg} / \mathrm{kg}$ i.p. $)$; (3) polymyxin B group (Pol), animals treated with $0.9 \%$ saline solution followed by $3 \times 2.5 \mathrm{mg} / \mathrm{kg}$ administrations i.p. of polymyxin $\mathrm{B}$ at different time-points $(4,8$, and $12 \mathrm{~h}$ ); (4) $\alpha$-amanitin plus polymyxin B group (Ama + Pol conc), animals concomitantly exposed to administration of one dose of $\alpha$-amanitin $(0.33 \mathrm{mg} / \mathrm{kg}$ i.p. $)$ and polymyxin $\mathrm{B}(1 \times 2.5 \mathrm{mg} / \mathrm{kg}$ i.p.); and (5) $\alpha$-amanitin plus polymyxin B group (Ama + Pol), animals exposed to $\alpha$-amanitin $(0.33 \mathrm{mg} / \mathrm{kg}$ i.p.) followed by $3 \times 2.5 \mathrm{mg} / \mathrm{kg}$ i.p. administrations of polymyxin $\mathrm{B}$ at different time-points (4, 8, and $12 \mathrm{~h}$ ). Body weight, motor activity, dyspnea, and overall welfare of the animals were observed every day, for 30 days.

\section{Short-term study (24 h) evaluations}

\section{Blood collection}

In the short-term study, blood was taken from the inferior vena cava into EDTA-containing tubes. The blood was immediately centrifuged at $920 \mathrm{~g}$ for $10 \mathrm{~min}\left(4{ }^{\circ} \mathrm{C}\right)$. The plasma supernatant was collected into tubes and stored at $-80{ }^{\circ} \mathrm{C}$ until determination of aspartate aminotransferase (AST), alanine aminotransferase (ALT), creatinine, urea, and total bilirubin. Plasma biochemical parameters were measured on an AutoAnalyzer (PRESTIGE 24i, PZ Cormay S.A.).

\section{Tissue processing for biochemical analysis}

After blood collection, liver and kidneys were removed, weighed, and processed as follows: (1) Slices of liver and 
kidney were kept in RNAlater and stored at $-80{ }^{\circ} \mathrm{C}$ for future total RNA quantification and quantitative PCR analysis; (2) segments of liver and kidney were placed in $4 \%$ paraformaldehyde [diluted in phosphate-buffered solution (PBS) $1 \mathrm{X}, 2.5 \%$ sucrose, $0.1 \%$ glutaraldehyde, $\mathrm{pH} 7.2$ 7.4] and used for histological and immunohistochemistry analysis; and (3) a section of liver and kidney was placed in complete RIPA buffer [50 mM Tris- $\mathrm{HCl}, 150 \mathrm{mM} \mathrm{NaCl}$, $1 \%$ Igepal CA-630 (v/v), $0.5 \%$ sodium deoxycholate $(\mathrm{w} / \mathrm{v})$, and $0.1 \%$ SDS (w/v), $\mathrm{pH} 7.4$, (supplemented with $0.25 \mathrm{mM}$ PMSF, $1 \mathrm{mM} \mathrm{Na} \mathrm{VO}_{4}, 10 \mathrm{mM} \mathrm{NaF}$, and $0.5 \%$ (v/v) complete protease inhibitor cocktail)] and stored at $-80{ }^{\circ} \mathrm{C}$ for carbonyl quantification.

\section{RNA extraction and real-time PCR}

Total RNA isolation was performed by adding $500 \mu \mathrm{L}$ of TRIzol reagent to liver and kidney samples according to the manufacturer's instructions. All specimens were homogenized by mechanical disruption using the Ultra-Turrax Mixer (IKAH) instrument, and total RNA was extracted in RNase-free environment. A DNase digestion step with RNase-free DNase set was included, and the total RNA obtained was resuspended in ultrapure water. The RNA concentration was determined by OD260 measurement using a NanoDropH ND-1000 Spectrophotometer (NanoDrop Technologies, USA), and the purity of the total RNA extracted was assessed by measuring the absorbance at 230 and $280 \mathrm{~nm}$. Of total RNA, $200 \mathrm{ng}$ was reverse-transcribed using the iScript Select cDNA Synthesis Kit according to the manufacturer's protocol. All cDNA samples were stored at $-20{ }^{\circ} \mathrm{C}$ until quantitative real-time PCR (qPCR) analysis. qPCR was performed in $\mathrm{iQ}^{\mathrm{TM}} 5$ RealTime PCR Detection System (Bio-Rad, Hercules, California, USA) in 96-well plates with a reaction volume of $20 \mu \mathrm{L}$ and runs up to 40 cycles using $\mathrm{iQ}^{\mathrm{TM}} \mathrm{SYBER}^{\circledR}$ Green Supermix. The final PCR mixture of $10 \mu \mathrm{L}$ contained $0.25 \mu \mathrm{L}$ of cDNA sample, $5 \mu \mathrm{L}$ of $\mathrm{iQ}^{\mathrm{TM}} \mathrm{SYBR}^{\circledR}$ Green Supermix, $0.25 \mu \mathrm{L}$ of each primer, and $4.25 \mu \mathrm{L}$ of RNase-free water. The cycling conditions were set as follows: Taq DNA polymerase activation at $95{ }^{\circ} \mathrm{C}$ for $3 \mathrm{~min}$; amplification steps: denaturation at $95{ }^{\circ} \mathrm{C}$ for $15 \mathrm{~s}$, annealing at $60{ }^{\circ} \mathrm{C}$ for $15 \mathrm{~s}$, and extension at $72{ }^{\circ} \mathrm{C}$ for $15 \mathrm{~s}$ with fluorescence acquisition. Two highly stable reference genes for RNAP II were chosen ( $\beta$-actin and GAPDH) as well as two ribosomal $18 \mathrm{~S}$ and $28 \mathrm{~S}$ genes transcribed by RNA polymerase I. All cDNA samples were measured in duplicate, and the relative transcript levels were quantified by the threshold cycle $\left(C_{\mathrm{t}}\right)$ value. All primers were designed using the Beacon Designer Software (version 7.2, PREMIER Biosoft International, Palo Alto, CA, USA).

\section{Histological analysis of liver and kidney}

In the short-term study, routine histological procedures for qualitative structural analysis of the liver and kidney were performed in four mice from each group. The $4 \%$ paraformaldehyde-fixed transverse section of the liver and kidney was processed for the routine hematoxylin-eosin staining. The slides were examined and photographed with a Carl Zeiss Imager A1 light microscope equipped with an AxioCam MRc 5 digital camera (Oberkochen, Germany). Histopathological evidences of tissue damage were calculated according to their severity and incidence in every slide (DoresSousa et al. 2015). Both liver and kidney, at least 50,000 cells per slide, were analyzed in a blind fashion in order to semiquantify the severity of the following parameters: (1) cellular degeneration, (2) interstitial inflammatory cell infiltration, (3) necrotic zones, and (4) loss of tissue organization. The severity of cellular degeneration was scored according to the number of cells showing any alterations (dilatation, vacuolization, pyknotic nuclei, and cellular density) in the light microscopy visual field: grade $0=$ no change from normal; grade $1=$ a limited number of isolated cells (until $5 \%$ of the total cell number); grade $2=$ groups of cells $(5-30 \%$ of cell total number); and grade $3=$ diffuse cell damage ( $30 \%$ of total cell number). The severity of necrosis was scored as follows: grade $0=$ no necrosis; grade $1=$ dispersed necrotic foci; grade $2=$ confluence necrotic areas; grade $3=$ massive necrosis. The inflammatory activity was graded semiquantitatively into: grade $0=$ no cellular infiltration; grade $1=$ mild leukocyte infiltration (1-3 cells by visual field); grade $2=$ moderate infiltration (4-6 leukocytes by visual field); and grade $3=$ heavy infiltration by neutrophils. The severity of tissue disorganization was scored according to the percentage of the affected tissue: score $0=$ normal structure; score $1=$ less than one-third of tissue; score $2=$ greater than one-third and less than two-thirds; and score $3=$ grater of two-thirds of tissue. For each visual field, the highest possible score was 12 and the lowest was 0 .

\section{Determination of NF- $\kappa B$ through immunohistochemistry}

In the short-term study, the determination of NF- $\mathrm{BB}$ nuclear translocation was performed in both liver and kidney. The $4 \%$ paraformaldehyde-fixed transverse section of the liver and kidney was processed as indicated in section "Histological analysis of liver and kidney," and then, the paraffinembedded tissues were deparaffinized. The deparaffinized tissues were rinsed in distilled water and incubated in PBS for $10 \mathrm{~min}$. Thereafter, antigens were unmasked by the microwave antigen-retrieval procedure: slides were immersed in $10 \mathrm{mM}$ citrate buffer, $\mathrm{pH} 6.0$, at $100^{\circ} \mathrm{C}$ and were placed in a full-powered microwave for $20 \mathrm{~min}$ and then cooled for 30 min. After washing four times (5 min each) with PBS, 
the sections were blocked with $3 \%$ bovine serum albumin (w/v) in PBS containing $0.05 \%$ Tween 20 (v/v) (PBS-T), for 30 min to suppress nonspecific binding. Following the blocking step, each slide was incubated with anti-NF- $\kappa \mathrm{B}$ p50 polyclonal rabbit antibody $(1: 50)$ in PBS-T overnight $\left(4^{\circ} \mathrm{C}\right)$. After washing four times (5 min each) with PBS, the sections were incubated for $2 \mathrm{~h}$, at $37^{\circ} \mathrm{C}$ with a goat anti-rabbit IgG alkaline phosphatase secondary antibody (1:100) in PBS-T. The sections were then washed four times $(5 \mathrm{~min})$ under gentle stirring and incubated with fast red reagent for $5 \mathrm{~min}$. After washing, the slides were then counterstained with a solution of hematoxylin/water (1:5) for $3 \mathrm{~min}$ and once again washed. Finally, slides were mounted in crystal mount medium with coverslips and analyzed by light microscopy. Negative controls were performed as described, with the omission of the primary antibody incubation step.

A minimum of 40 cells per area were evaluated, and for each section, six areas in each zone were seen. In the liver, cell quantification was possible and the number of nuclear staining in hepatocytes and macrophage-like cells was expressed in number of positive cells per area $\left(\mu \mathrm{m}^{2}\right)$.

\section{Protein carbonylation assay}

In the short-term study, protein carbonylation, an index of protein oxidation, was determined in the liver and in the kidneys. Liver and kidney sections were homogenized in ice-cold RIPA buffer through sonication. The homogenates were centrifuged at $13,000 \mathrm{~g}$, for $10 \mathrm{~min}$, at $4{ }^{\circ} \mathrm{C}$, and supernatants were kept at $-80{ }^{\circ} \mathrm{C}$ until analysis. Samples containing $20 \mu \mathrm{g}$ of protein were then processed as previously described (Barbosa et al. 2012). Immunoreactive bands were detected using the Clarity ${ }^{\mathrm{TM}}$ Western ECL Substrate, according to the supplier's instructions, and digital images were acquired using a Molecular Imager ${ }^{\circledR}$ ChemiDocTM XRS + System (Bio-Rad Laboratories, California, USA) and analyzed with Image Lab ${ }^{\mathrm{TM}}$ Software (Bio-Rad Laboratories California, USA). Optical density results were expressed as \% of control values.

\section{Statistical analysis}

All data obtained were expressed as mean \pm standard deviation (SD). All statistical analysis was performed using GraphPad Prism ${ }^{\circledR}$ (version 6.00, GraphPad Software, San Diego, California, USA). Comparisons among the survival curves were performed using log-rank (Mantel-Cox) test. The Shapiro-Wilk test was performed to check normality of the data. Statistical comparisons were done using the oneway ANOVA (in case of normal distribution) followed by the Bonferroni post hoc test or Kruskal-Wallis (in case not normal distribution) followed by the Dunn's post hoc test. $p$ values $<0.05$ were considered as statistically significant.

\section{Results}

\section{In silico study}

\section{Identification of critical residues for polymyxin B binding}

A docking study to determine the preferred orientation of polymyxin B within RNAP II. To gain a broader insight of the most important residues for the dynamical interactions between these two molecules we performed and analyzed $10 \mathrm{~ns}$ of MD simulations of the RNAP II/ polymyxin B docked complex. Figure 1 shows superposition of the average structures of $\alpha$-amanitin polymyxin $B$ during the simulations. The polymyxin B binding site is located in the same interface of $\alpha$-amanitin. In order to more easily and accurately grasp the interactions between the RNAP II and polymyxin B, an energy decomposition analysis of the simulations was also done (Table 1). We resorted to the MM-GBSA method, since computational studies using MM-GBSA calculations on different complexes of protein/ligands showed good correlations with experimental data (Onufriev et al. 2000). Our aim was to investigate the interaction features in detail and obtain insights into the contribution of each component to the RNAP II/polymyxin B binding. The individual energy decompositions of all residues in the complex were calculated in order to identify key residues involved in polymyxin B binding to RNAP II.

Figure 2 depicts the relative position of the polymyxin B and important residues in the binding complex by using the lowest root-mean-square deviation (RMSD) structure with respect to the average of the simulation. The polymyxin $\mathrm{B}$ interacts with residues Arg720, Ala1087, Gly1088, Val1089, Val1094, Met1285, Ala1357, and Gly1360. The guanidinium group of Arg726 forms dipole/dipole interactions with L- $\alpha-\gamma$-diaminobutyric acid (Dab) residue of polymyxin $\mathrm{B}$, which corresponds to energy of $-1.97 \mathrm{kcal} /$ mol. The binding energy of residue Ala1087 backbone is $-1.41 \mathrm{kcal} / \mathrm{mol}$, thus agreeing with a hydrogen bond between Ala1087 oxygen atom and polymyxin B N22 (Table 2). At the same time, Gly1088 main chain oxygen atom also forms a hydrogen bond with polymyxin B N15 $(-2.81 \mathrm{kcal} / \mathrm{mol})$ (Table 2). Dipole/dipole interactions were observed between Val1089 and polymyxin B $(-2.25 \mathrm{kcal} / \mathrm{mol})$. Hydrophobic interactions may be the main force between Val1094 and side chain leucine residue of polymyxin $\mathrm{B}$, which corresponds to energy of $-2.25 \mathrm{kcal} / \mathrm{mol}$. Met1285 alkyl group forms $\mathrm{CH} / \pi$ interactions with polymyxin B phenyl group $(-1.83 \mathrm{kcal} /$ mol). Finally, Ala1357 and Gly1360 alkyls groups interact with polymyxin B methyl-octanoic acid group by hydrophobic interactions $(-0.63 \mathrm{kcal} / \mathrm{mol})$. 
Fig. 1 Superposition of RNAP II average structure $/ \alpha$-amanitin (cyan) and RNAP II average structure/polymyxin B (magenta) (representation of $\alpha$-amanitin is in red and of polymyxin B is in yellow) (color figure online)

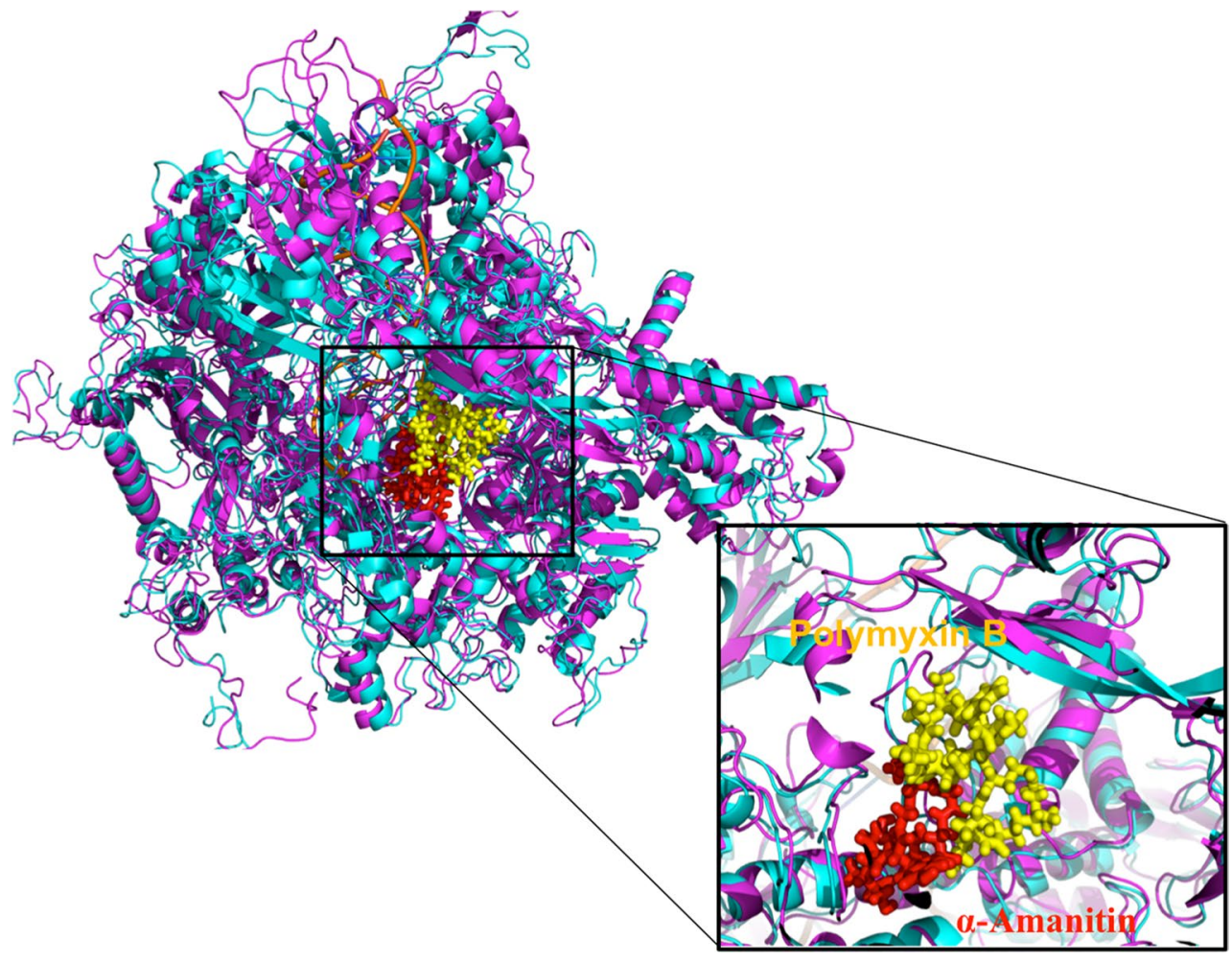

Table 1 Binding energy calculation between the polymyxin B and Rpb1 and Rpb2 subunits (all energies are in $\mathrm{kcal} / \mathrm{mol}$ )

\begin{tabular}{lccccccccc}
\hline Complex & $\Delta G_{\text {ele }}$ & $\Delta G_{\mathrm{vdw}}$ & $\Delta G_{\text {Int }}$ & $\Delta G_{\text {Gas }}$ & $\Delta G_{\mathrm{GBSUR}}$ & $\Delta G_{\mathrm{GB}}$ & $\Delta G_{\text {GBsol }}$ & $\Delta G_{\text {GBele }}$ & $\Delta G_{\mathrm{tot}}$ \\
\hline RNAP II/polymyxin B & -62.50 & -57.64 & 0.00 & -120.14 & -8.45 & 110.40 & 101.95 & 47.90 & -18.19
\end{tabular}

$\Delta G_{\text {ele }}$ electrostatic energy; $\Delta G_{\mathrm{vdw}}$ van der Waals energy; $\Delta G_{\text {int }}$ internal energy; $\Delta G_{\text {Gas }}$ total gas-phase energy (sum $\Delta G_{\text {ele }}, \Delta G_{\text {vdw }}, \Delta G_{\text {int }}$ ); $\Delta G_{\mathrm{GBSUR}}$ nonpolar contribution to solvation; $\Delta G_{\mathrm{GB}}$ the electrostatic contribution to the solvation free energy; $\Delta G_{\mathrm{GBSOL}}$ sum of nonpolar and polar contributions to solvation; $\Delta G_{\mathrm{GBELE}}$ sum of the electrostatic solvation free energy and electrostatic energy; $\Delta G_{\mathrm{TOT}}$ estimated total binding energy

\section{Polymyxin B abolished the increase in plasma aminotransferases levels elicited by $\alpha$-amanitin}

Plasma biomarkers were determined at $24 \mathrm{~h}$ after $\alpha$-amanitin administration as shown in Fig. 3. AST and ALT were significantly increased in the $\alpha$-amanitin group $(359.10 \pm 190.40$ and $120.20 \pm 83.20 \mathrm{U} / \mathrm{L}$ for AST and ALT, respectively) as compared to control group $(63.80 \pm 8.63$ and $37.80 \pm 6.94 \mathrm{U} / \mathrm{L}$ for AST and ALT, respectively). This increase in effect was prevented with the $3 \times 2.5 \mathrm{mg} / \mathrm{kg}$ administration of polymyxin B $(68.46 \pm 23.92$ and $32.70 \pm 8.45 \mathrm{U} / \mathrm{L}$ for AST and ALT, respectively) (Fig. 3a, b). On the other hand, urea and creatinine show a small tendency to increase in the $\alpha$-amanitin group, however, without reaching statistical significance (Fig. 3c, d). The ratio AST/ALT and the total bilirubin showed no differences between treatments (Fig. 3e, f).
$\alpha$-Amanitin caused significant decrease in hepatic weight

As an indirect measure of organ damage, we quantified the ratio of both liver and kidney weight to total body weight in the 24-h study (Table 3). The relative liver weight from the $\alpha$-amanitin group showed a significant decrease $(5.75 \pm 0.58 \mathrm{mg} / \mathrm{g})$ in comparison with control group $(6.77 \pm 0.64 \mathrm{mg} / \mathrm{g})$, and the treatment with polymyxin B prevented this effect $(5.94 \pm 0.52 \mathrm{mg} / \mathrm{g})$ (Table 3). No differences were seen in ratios of kidney weight/body weight values among control and treatment groups.

Polymyxin B prevented the total RNA decrease in the kidney of $\alpha$-amanitin-treated animals

Since $\alpha$-amanitin rapidly inactivates RNAP II with a consequent decrease in mRNA transcription, we quantified the total RNA content in the liver and kidneys of animals in 


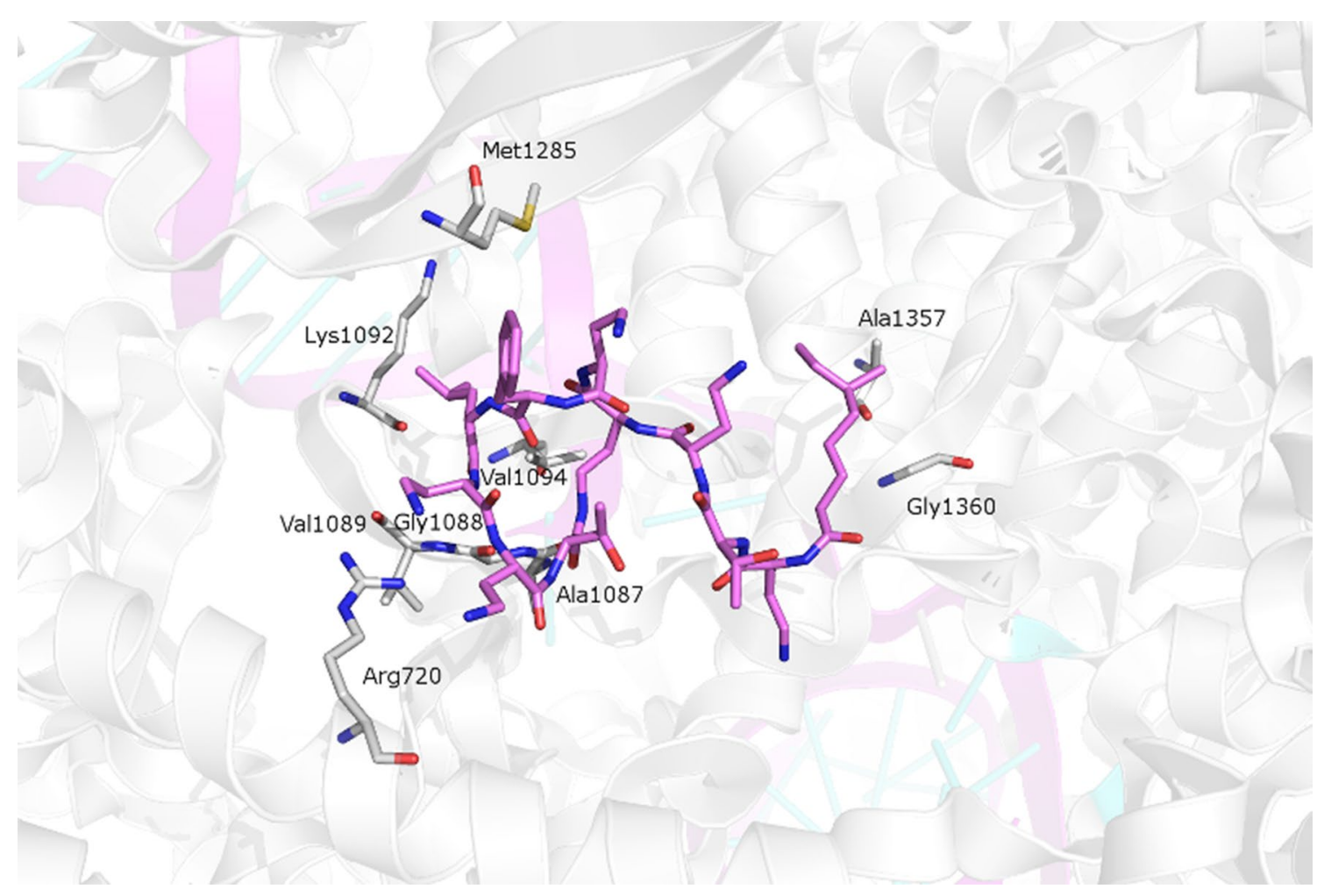

Fig. 2 RNAP II geometries of key residues that produce some favorable interactions with polymyxin B, plotted in the complexes, according to the average structure from the MD trajectory

Table 2 Hydrogen bonds formed between the polymyxin $\mathrm{B}$ and RNA polymerase $\mathrm{II}^{\mathrm{a}}$

\begin{tabular}{llllll}
\hline Toxin/antidote & Donor & AcceptorH & Acceptor & Distance $^{\mathrm{b}}(\AA)$ & Angle $^{\mathrm{b}}\left(^{\circ}\right)$ \\
\hline Polymyxin B & Ala1087:O & Polymyxin B:2H14 & Polymyxin B:N22 & 2.48 & 140.27 \\
& Gly1088:O & Polymyxin B:2H10 & Polymyxin B:N15 & 1.82 & 168.67 \\
& Val1089:N & Polymyxin B:2H10 & Polymyxin B:N15 & 2.11 & 148.55 \\
\hline
\end{tabular}

${ }^{\text {a }}$ Hydrogen bonds were analyzed in the average structures from MD simulation

b The geometric criterion for the formation of H-bonds is common with an acceptor/donor distance $<3.5 \AA$ and the donor-H-acceptor angle larger than $120^{\circ}$ all experimental groups. These total RNA levels were further normalized to organ weight. Results from $\alpha$-amanitinintoxicated animals revealed that the kidney total RNA significantly decreased $(0.981 \pm 0.645 \mu \mathrm{g} / \mathrm{mg}$ kidney $)$ compared with control $(3.331 \pm 0.466 \mu \mathrm{g} / \mathrm{mg}$ kidney) (Fig. 4a). This effect was reverted in the $\alpha$-amanitin plus polymyxin B group $(3.622 \pm 1.550 \mu \mathrm{g} / \mathrm{mg}$ kidney). On the other hand, no differences were found for total RNA in the liver of $\alpha$-amanitin-intoxicated animals (Fig. 4b).

\section{Polymyxin B abrogated the $\alpha$-amanitin-induced alteration of the transcription process}

The evaluation of the genetic transcription by RNAP II was based on GAPDH and $\beta$-actin mRNA quantitative analysis.
The relative transcript levels were quantified by the threshold cycle $(\mathrm{Ct})$ value, which increases with a decreasing amount of template.

Data from $\alpha$-amanitin-intoxicated kidney indicated that the transcription of GAPDH and $\beta$-actin mRNA significantly decreased $(16.29 \pm 1.31$ and $17.83 \pm 0.36$, respectively) when compared to control group (12.98 \pm 0.46 and $14.20 \pm 0.3$, respectively) (Table 4). This effect was reverted in the $\alpha$-amanitin plus polymyxin B group $(13.16 \pm 0.30$ and $15.08 \pm 0.68$ for GAPDH and $\beta$-actin mRNA, respectively).

Although the transcript levels of GAPDH mRNA in the liver samples of $\alpha$-amanitin-treated group showed a tendency to decrease $(17.28 \pm 5.47)$, it failed to reach statistically significance. Nevertheless, this $\alpha$-amanitin-treated 
Fig. 3 Plasma levels of a aspartate aminotransferase (AST), b alanine aminotransferase (ALT), c urea d creatinine e ratio AST/ ALT and $\mathbf{f}$ total bilirubin in control, $3 \times 2.5 \mathrm{mg} / \mathrm{kg}$ polymyxin B (Pol), $0.33 \mathrm{mg} / \mathrm{kg} \alpha$-amanitin (Ama), and $\alpha$-amanitin plus polymyxin B (Ama $+\mathrm{Pol})$ groups. Results are presented as mean \pm standard deviation and were obtained from 4 to 5 animals from each treatment. Statistical comparisons were made using Kruskal-Wallis ANOVA on ranks followed by the Dunn's post hoc test $(* p<0.05$, Ama vs. control; ${ }^{\#} p<0.05$, Ama vs. Ama + Pol)
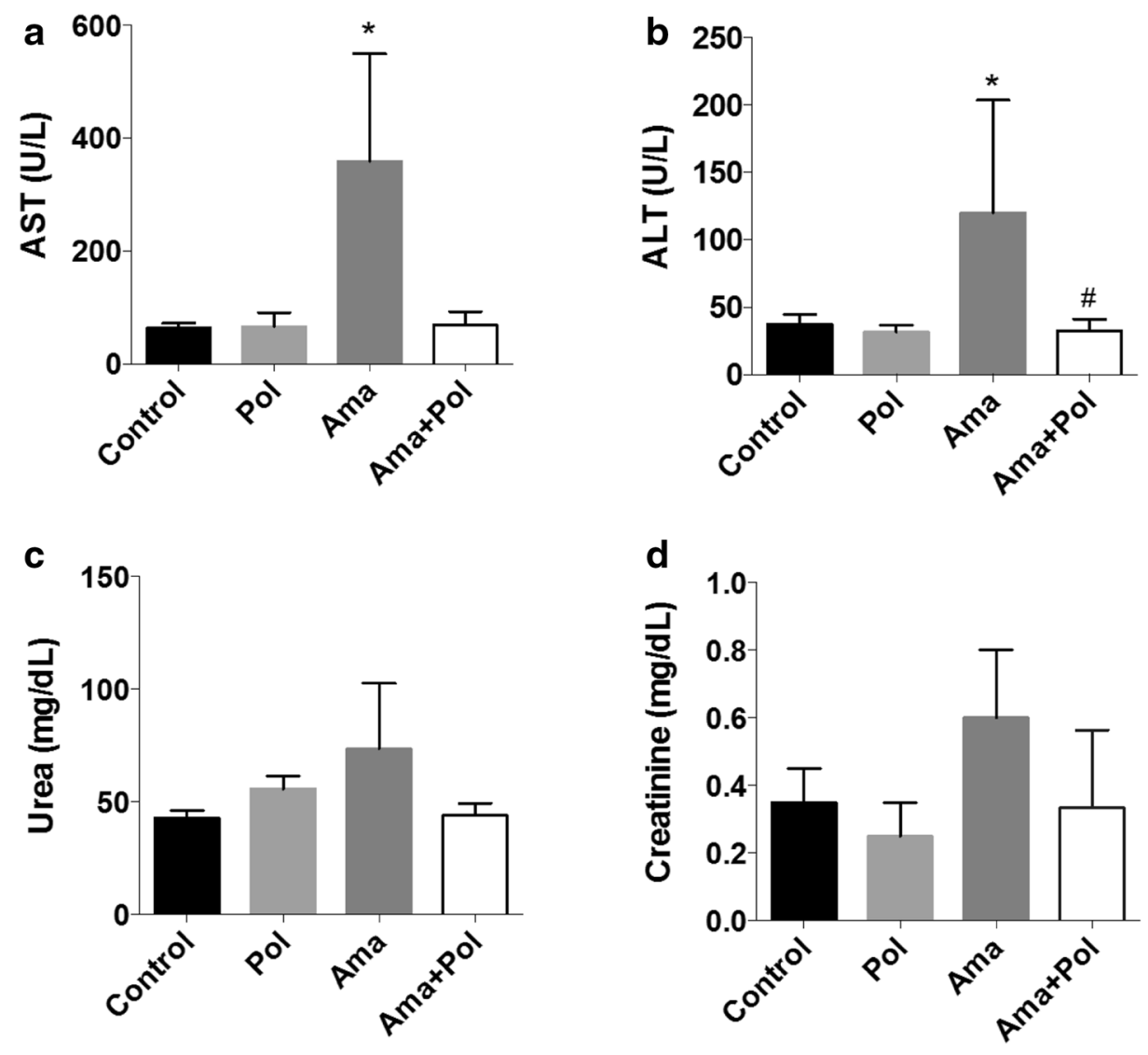

e

f
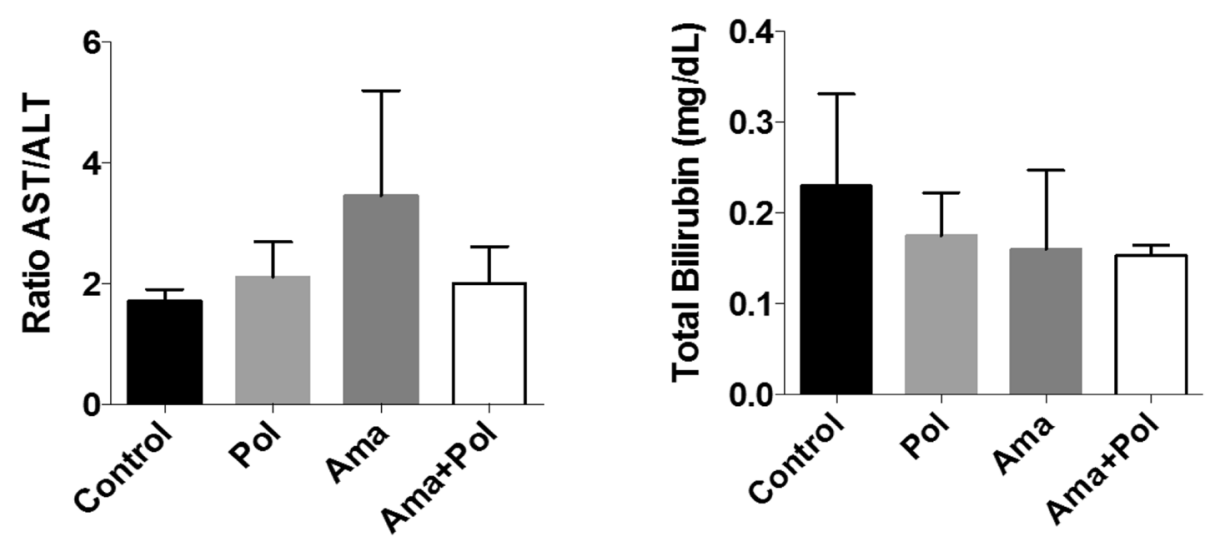

Table 3 Ratios of liver weight/body weight and kidney weight/body weight

\begin{tabular}{lllll}
\hline & Control & Polymyxin B & $\alpha$-Amanitin & $\begin{array}{c}\alpha \text {-Amanitin }+ \\
\text { polymyxin B }\end{array}$ \\
\hline Liver & $6.77 \pm 0.64$ & $6.04 \pm 0.26$ & $5.75 \pm 0.58^{*}$ & $5.94 \pm 0.52$ \\
Kidney & $0.97 \pm 0.03$ & $0.85 \pm 0.11$ & $0.92 \pm 0.09$ & $0.85 \pm 0.10$ \\
\hline
\end{tabular}

Results are presented as means \pm standard deviation from 4 animals of each treatment group. Statistical comparisons were made using the one-way ANOVA followed by Dunn's post hoc test $(* p<0.05$ vs. control) tendency was reverted by the treatment with polymyxin $\mathrm{B}$ $(14.80 \pm 1.24)$.

On the other hand, no differences were found for $\beta$-actin mRNA levels for liver samples (Table 4). Importantly, RNA polymerase I was not affected by $\alpha$-amanitin poisoning since the transcription of ribosomal proteins S18 and S28 by RNA polymerase I was always similar, regardless of the organ or experimental group analyzed (Table 4). 


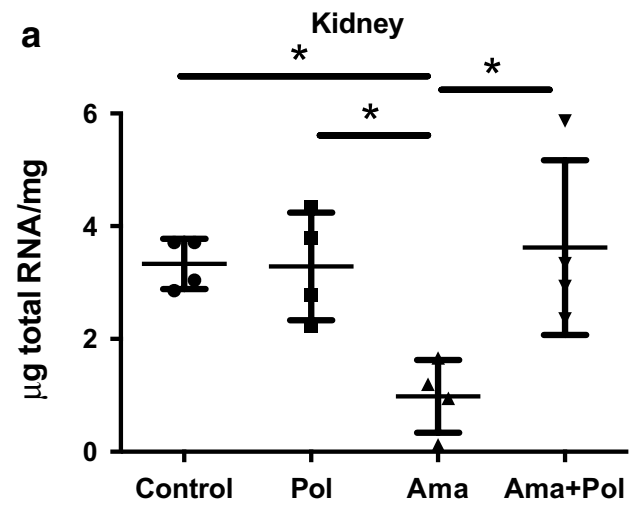

Fig. 4 a Total RNA liver levels and b total RNA kidney levels of control, $3 \times 2.5 \mathrm{mg} / \mathrm{kg}$ polymyxin $\mathrm{B}(\mathrm{Pol}), 0.33 \mathrm{mg} / \mathrm{kg} \alpha$-amanitin (Ama), and $\alpha$-amanitin plus polymyxin B (Ama + Pol) groups. Results were obtained from four animals from each treatment group. b Liver

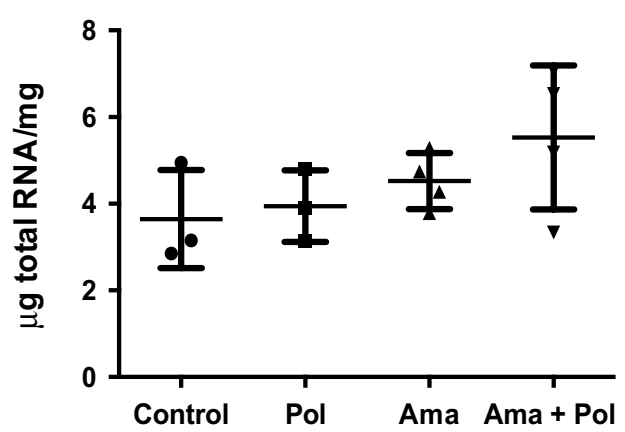

Table 4 Relative mRNA levels of S28, S18, GAPDH, and $\beta$-actin genes in liver and kidney samples

\begin{tabular}{|c|c|c|c|c|}
\hline & \multicolumn{2}{|l|}{ RNAP I } & \multicolumn{2}{|l|}{ RNAP II } \\
\hline & $\mathrm{S} 18$ & $\mathrm{~S} 28$ & GAPDH & $\beta$-Actin \\
\hline \multicolumn{5}{|l|}{ Liver } \\
\hline Control & $14.75 \pm 1.41$ & $17.27 \pm 0.68$ & $14.55 \pm 1.46$ & $17.44 \pm 2.47$ \\
\hline Polymyxin B & $14.60 \pm 1.82$ & $17.95 \pm 1.51$ & $14.75 \pm 1.41$ & $17.31 \pm 1.59$ \\
\hline$\alpha$-Amanitin & $13.68 \pm 0.61$ & $16.87 \pm 0.36$ & $17.28 \pm 5.47$ & $16.10 \pm 1.77$ \\
\hline $\begin{array}{l}\alpha \text {-Amanitin }+ \text { polymyxin } \mathrm{B} \\
\text { Kidney }\end{array}$ & $13.97 \pm 0.46$ & $17.52 \pm 0.42$ & $14.80 \pm 1.24$ & $16.47 \pm 1.33$ \\
\hline Control & $14.09 \pm 0.83$ & $17.06 \pm 0.82$ & $12.98 \pm 0.46$ & $14.20 \pm 0.37$ \\
\hline Polymyxin B & $13.84 \pm 0.35$ & $16.84 \pm 0.42$ & $12.49 \pm 0.38$ & $14.89 \pm 0.44$ \\
\hline$\alpha$-Amanitin & $13.95 \pm 1.72$ & $17.37 \pm 1.36$ & $16.29 \pm 1.31^{* * * * *}$ & $17.83 \pm 0.36^{* * * *}$ \\
\hline $\begin{array}{l}\alpha \text {-Amanitin }+ \\
\text { polymyxin B }\end{array}$ & $13.55 \pm 0.89$ & $16.82 \pm 0.69$ & $13.16 \pm 0.30^{\# \# \# ~}$ & 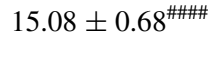 \\
\hline
\end{tabular}

Results are presented as mean \pm standard deviation of threshold cycles from 4 animals from each treatment group. Statistical comparisons were made using ANOVA followed by Bonferroni post hoc test

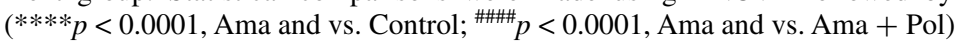

\section{Polymyxin B prevented $\alpha$-amanitin-induced renal and hepatic histological damage}

Given the known toxic effects of $\alpha$-amanitin in the liver and kidneys, we proceeded to a histopathological analysis to evaluate the putative protective tissue effects of the polymyxin B antidote. As expected, liver samples from the control and polymyxin B groups presented a normal structure at light microscopy, without evidences of edema, necrosis, or cellular infiltrations (Fig. 5b; Table 5). On the other hand, $\alpha$-amanitin caused prominent hepatic cellular edema, cytoplasmic vacuolization, and interstitial inflammatory cell infiltration (Fig. 5c; Table 5). Moreover, the $\alpha$-amanitin group showed some necrotic foci in the liver (Fig. 5c; Table 5), which were more evident in the centrilobular zone. The group of $\alpha$-amanitin plus polymyxin $B$ showed a significant decrease in $\alpha$-amanitin-induced necrosis, edema, and cytoplasmic vacuolization (Fig. 5d; Table 5). However, polymyxin B was not able to prevent the $\alpha$-amanitininduced increase in interstitial infiltration of inflammatory cells (Fig. 5d; Table 5).

Regarding the kidney, control and polymyxin B groups presented a normal renal structure at light microscopy (Fig. 6a, b; Table 5). Histological examination of $\alpha$-amanitin-treated kidney (Fig. 6c; Table 5) revealed severe degenerative changes: (1) The renal corpuscles appear heterogeneous, with a wide capsular space, and thickened external Bowman capsule; (2) proximal tubules showed necrotic cells vacuolization and edema; and (3) distal tubules cells had signs of atrophy and degeneration, while a large amount 

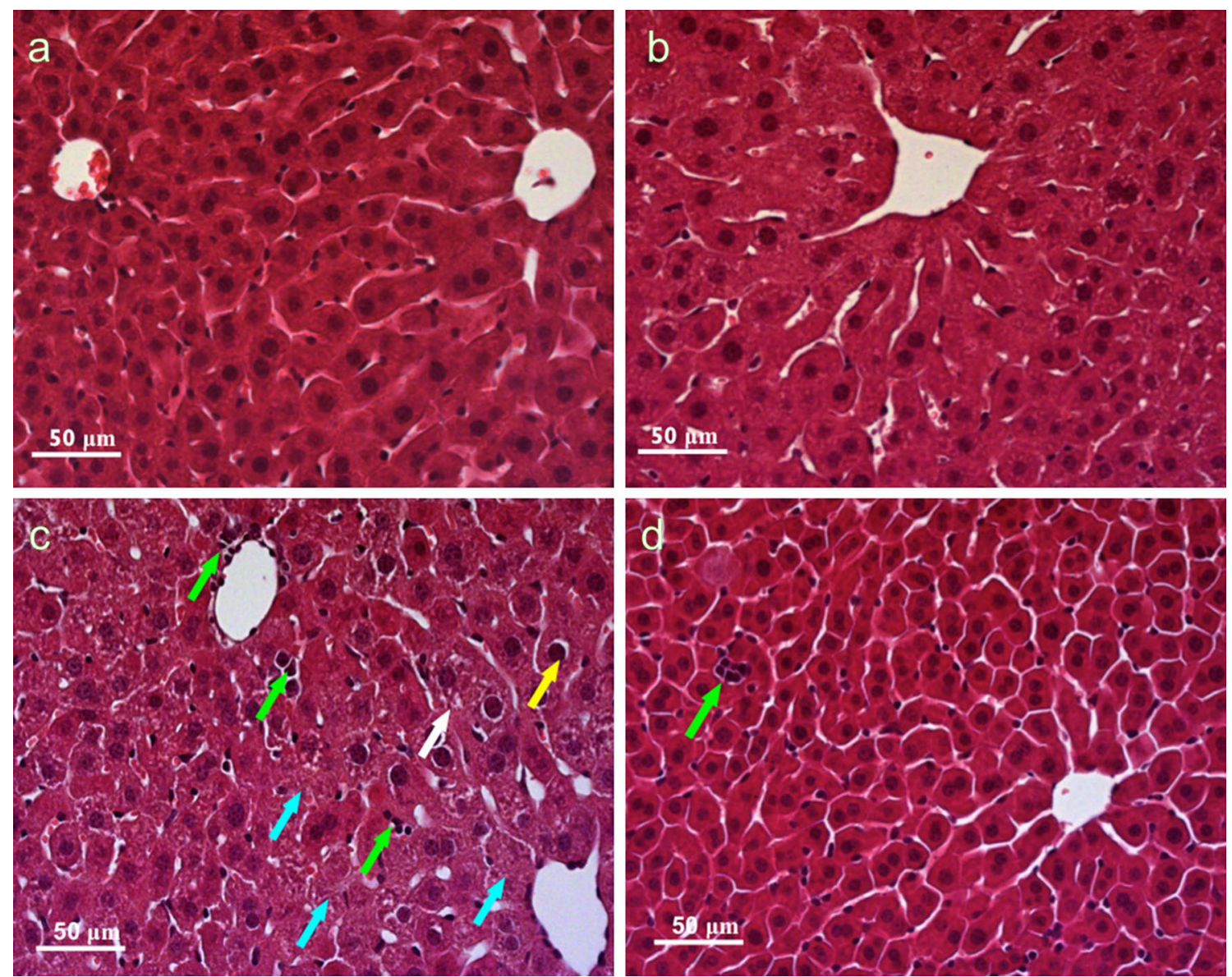

Fig. 5 Liver histology: a light micrograph from the control group showing normal morphology and structure; b light micrograph from the polymyxin B group showing normal morphology and structure; c light micrograph from $\alpha$-amanitin group. The presence of cellular edema (yellow arrow), cytoplasmic vacuolization (white arrow), inflammatory cells (green arrows), as well as some necrotic zones can be seen (cyan arrows); $\mathbf{d}$ light micrograph from $\alpha$-amanitin plus polymyxin B group. The edema and cytoplasmic vacuolization and necrosis were significantly attenuated by polymyxin B (color figure online)
Table 5 Semiquantitative analysis of the morphological injury parameters of control, $\alpha$-amanitin, and $\alpha$-amanitin plus polymyxin B groups

\begin{tabular}{|c|c|c|c|c|}
\hline & Control & Polymyxin B & $\alpha$-Amanitin & $\alpha$-Amanitin + polymyxin $B$ \\
\hline \multicolumn{5}{|l|}{ Liver } \\
\hline Cellular degeneration & $0.00 \pm 0.00$ & $0.25 \pm 0.44$ & $2.02 \pm 0.42^{* * * *}$ & 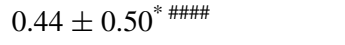 \\
\hline Necrosis & $0.00 \pm 0.00$ & $0.16 \pm 0.49$ & $1.62 \pm 0.49^{* * * * *}$ & 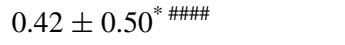 \\
\hline Inflammatory activity & $0.25 \pm 0.43$ & $0.23 \pm 0.42$ & $2.09 \pm 0.35^{* * * * *}$ & $2.04 \pm 0.20^{* * * *}$ \\
\hline \multicolumn{5}{|l|}{ Kidney } \\
\hline Cellular degeneration & $0.27 \pm 0.45$ & $0.20 \pm 0.41$ & $2.26 \pm 0.44^{* * * *}$ & 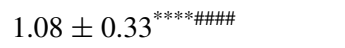 \\
\hline Necrosis & $0.00 \pm 0.00$ & $0.00 \pm 0.00$ & $2.06 \pm 0.62^{* * * *}$ & 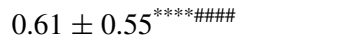 \\
\hline Inflammatory activity & $0.22 \pm 0.42$ & $0.19 \pm 0.40$ & $1.81 \pm 0.42^{* * * *}$ & $1.66 \pm 0.48^{* * * *}$ \\
\hline
\end{tabular}

Results of hematoxylin-eosin staining, given in scores, are presented as means \pm standard deviation from 4 animals from each treatment group. Statistical comparisons were made using Kruskal-Wallis ANOVA on Ranks followed by the Dunn's post hoc test $(* p<0.05$, $* * * *<0.0001$, treatment vs. control; $\#$ \#\#\# $p<0.0001$, Ama group vs Ama $+\mathrm{Pol})$ of a protein-related material caused enlargement and obstruction of these tubules (Fig. 6c). Noteworthy, in the $\alpha$-amanitin plus polymyxin group, the damage induced by $\alpha$-amanitin was significantly attenuated, particularly regarding the necrotic foci and the obstruction of distal tubules (Fig. 6d; Table 5). 

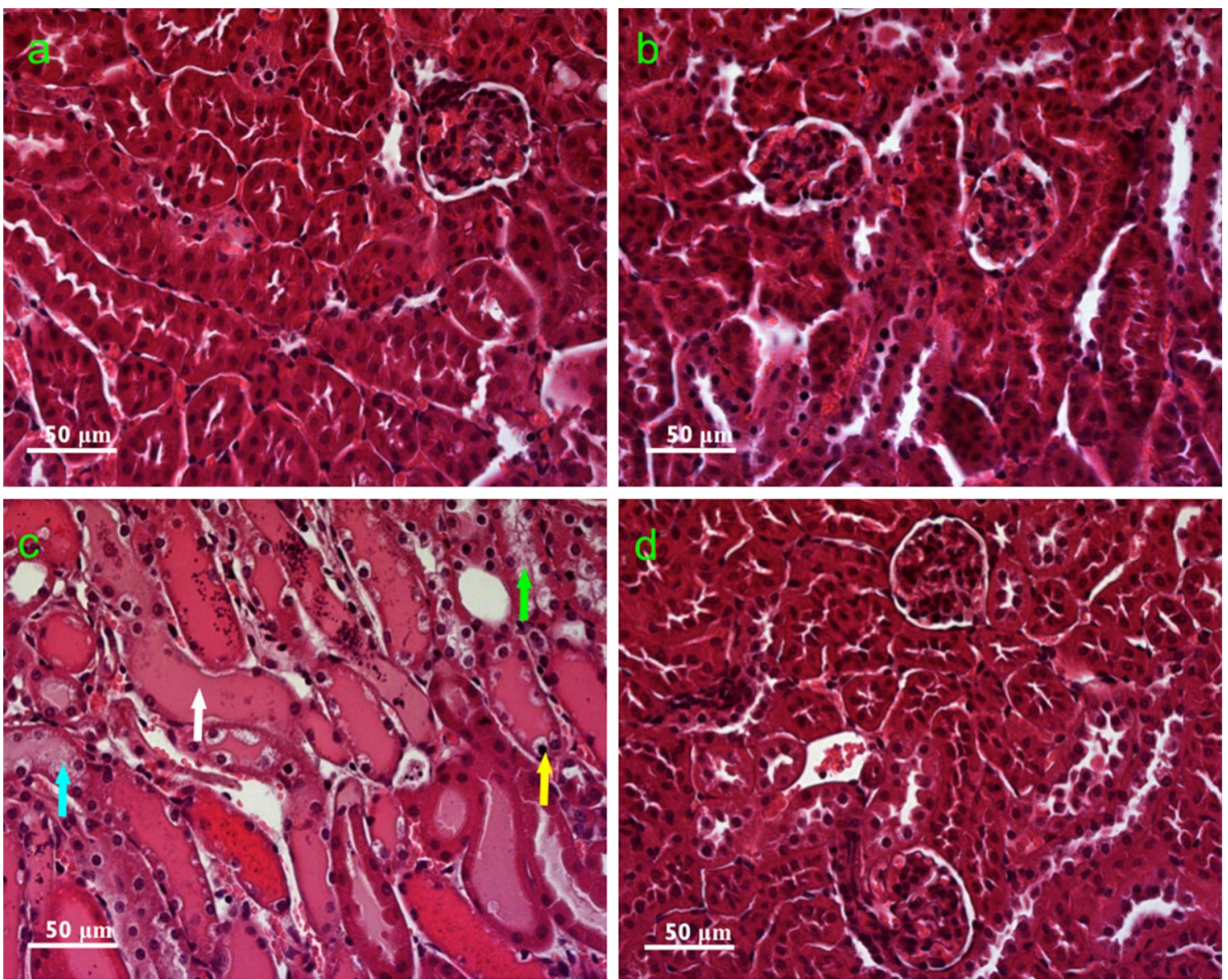

Fig. 6 Kidney histopathology: a light micrograph from the control group showing normal morphology and structure; b light micrograph from the polymyxin B group showing normal morphology and structure; $\mathbf{c}$ light micrograph from $\alpha$-amanitin group. The presence of cellular edema (yellow arrow), cytoplasmic vacuolization (green arrow), and large amounts of protein-related material cause enlargement and

$\alpha$-Amanitin caused $N F-\kappa B$ nuclear translocation that was not reverted by polymyxin $B$

The translocation of the NF- $\mathrm{BB}$ factor to the nuclei was assessed by immunohistochemistry in the liver and kidney (Figs. 7, 8) in the short-term study. The liver of control and polymyxin B groups showed mainly cytoplasmic staining without marked nuclear staining cells (Fig. 7a, b). On the other hand, $\alpha$-amanitin caused significant nuclear translocation of NF-kB mainly in the macrophage-like cells $\left(0.0397 \pm 0.0168\right.$ cells $\left./ \mu \mathrm{m}^{2}\right)$ when compared to control group $\left(0.0018 \pm 0.0027 \mathrm{cells} / \mu \mathrm{m}^{2}\right)$ (Fig. $\left.7 \mathrm{c}, \mathrm{e}\right)$. Moreover, $\alpha$-amanitin was also able to cause a significant increase in hepatocytes staining positive as a result of activated nuclear NF-кB $\left(0.0151 \pm 0.0093\right.$ cells $\left./ \mu \mathrm{m}^{2}\right)$ (Fig. 7c, f) when compared to the control group $\left(0.0012 \pm 0.0049 \mathrm{cells} / \mu \mathrm{m}^{2}\right)$. The $\alpha$-amanitin plus polymyxin B group $(0.0048 \pm 0.0319$ and $0.0019 \pm 0.0129$ cells $/ \mu \mathrm{m}^{2}$ for macrophage-like cells obstruction of distal tubules (white arrow), and some necrotic zones can be seen (cyan arrow); d light micrograph from $\alpha$-amanitin plus polymyxin B group. The obstruction of distal tubules, edema, cytoplasmic vacuolization, and necrosis were significantly attenuated after polymyxin B (color figure online)

and hepatocytes, respectively) showed similar results to $\alpha$-amanitin group; therefore, polymyxin B was not able to revert the pro-inflammatory effects of $\alpha$-amanitin (Fig. 7d-f).

Regarding the kidneys, the results showed predominant cytoplasmic staining in control and polymyxin B groups (Fig. 8a, b), whereas in both $\alpha$-amanitin and $\alpha$-amanitin plus polymyxin $\mathrm{B}$ groups an increase in macrophage-like cells staining positive for activated NF- $\kappa \mathrm{B}$ was observed (Fig. 8c, d). Due to the heterogeneity of the tissue, the accurate nuclear staining count of the type of cell marked was difficult; therefore, only the representative light micrographs of the kidney (Fig. 8) are presented.

\section{Polymyxin B prevented the $\alpha$-amanitin increase in hepatic protein carbonylation}

Protein carbonylation is an indicator of severe oxidative damage, which often leads to a loss of protein function. As shown 

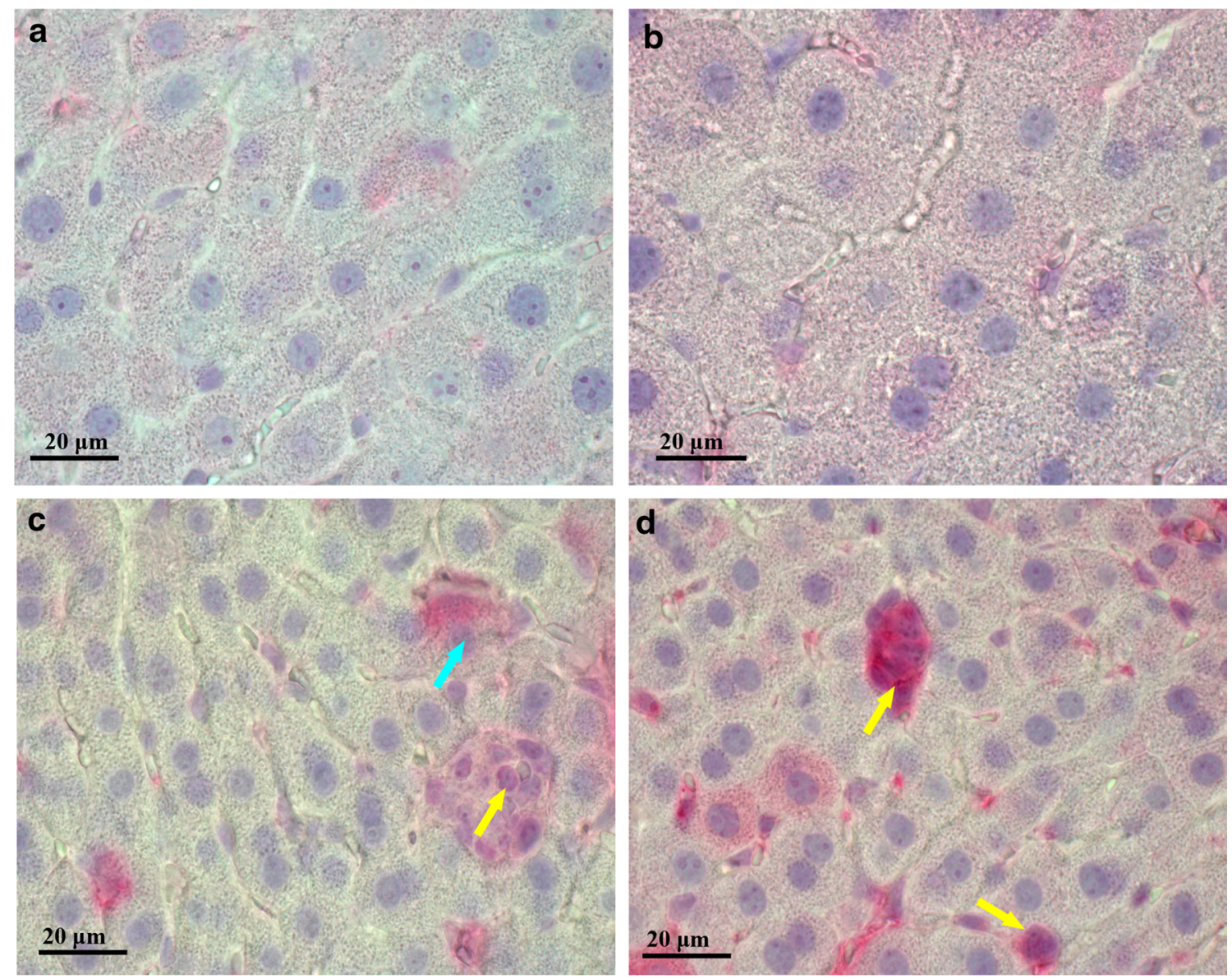

e

f
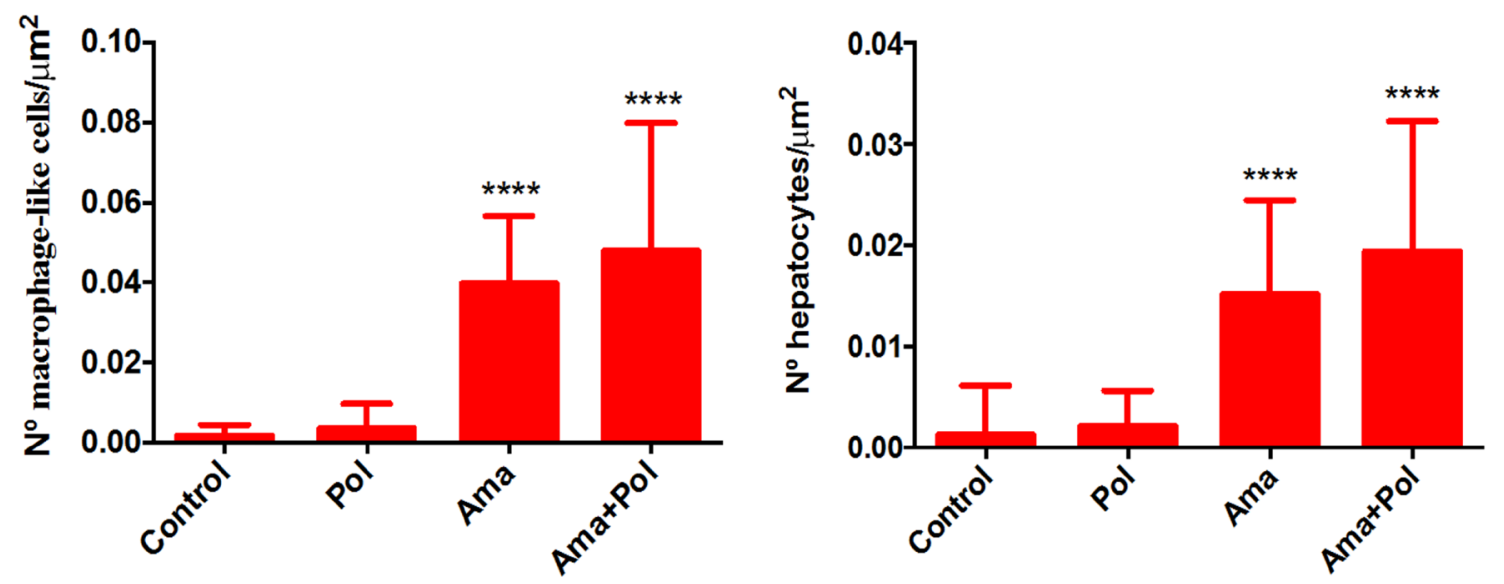

Fig. 7 Immunohistochemistry of NF-kB activation in the liver by light microscopy: a light micrograph from the control group showing only cytoplasmic staining without marked nuclear staining cells; b light micrograph from polymyxin B group showing only cytoplasmic staining without marked nuclear staining cells; c light micrograph from $\alpha$-amanitin group showing a higher number of cell staining positive for activated NF- $\mathrm{B}$ in the macrophage-like cells (yellow arrows) and in the hepatocytes (cyan arrows). d Light micrograph from $\alpha$-amanitin plus polymyxin B group showing a higher number of cells staining positive for activated NF-кB in the

macrophage-like cells (yellow arrow). e Number of macrophagelike cells staining positive for activated NF- $\mathrm{BB}$. f Number of hepatocytes staining positive for activated NF- $\mathrm{KB}$ of control, $3 \times 2.5 \mathrm{mg} / \mathrm{kg}$ polymyxin B (Pol), $0.33 \mathrm{mg} / \mathrm{kg} \alpha$-amanitin (Ama), and $\alpha$-amanitin plus polymyxin B (Ama $+\mathrm{Pol})$ groups. Results were expressed as mean \pm standard deviation. Results were obtained from four animals from each treatment group. Statistical comparisons were made using Kruskal-Wallis ANOVA on ranks followed by the Dunn's post hoc test $(* * * * p<0.0001$, Ama and Ama + Pol vs. control) (color figure online) 

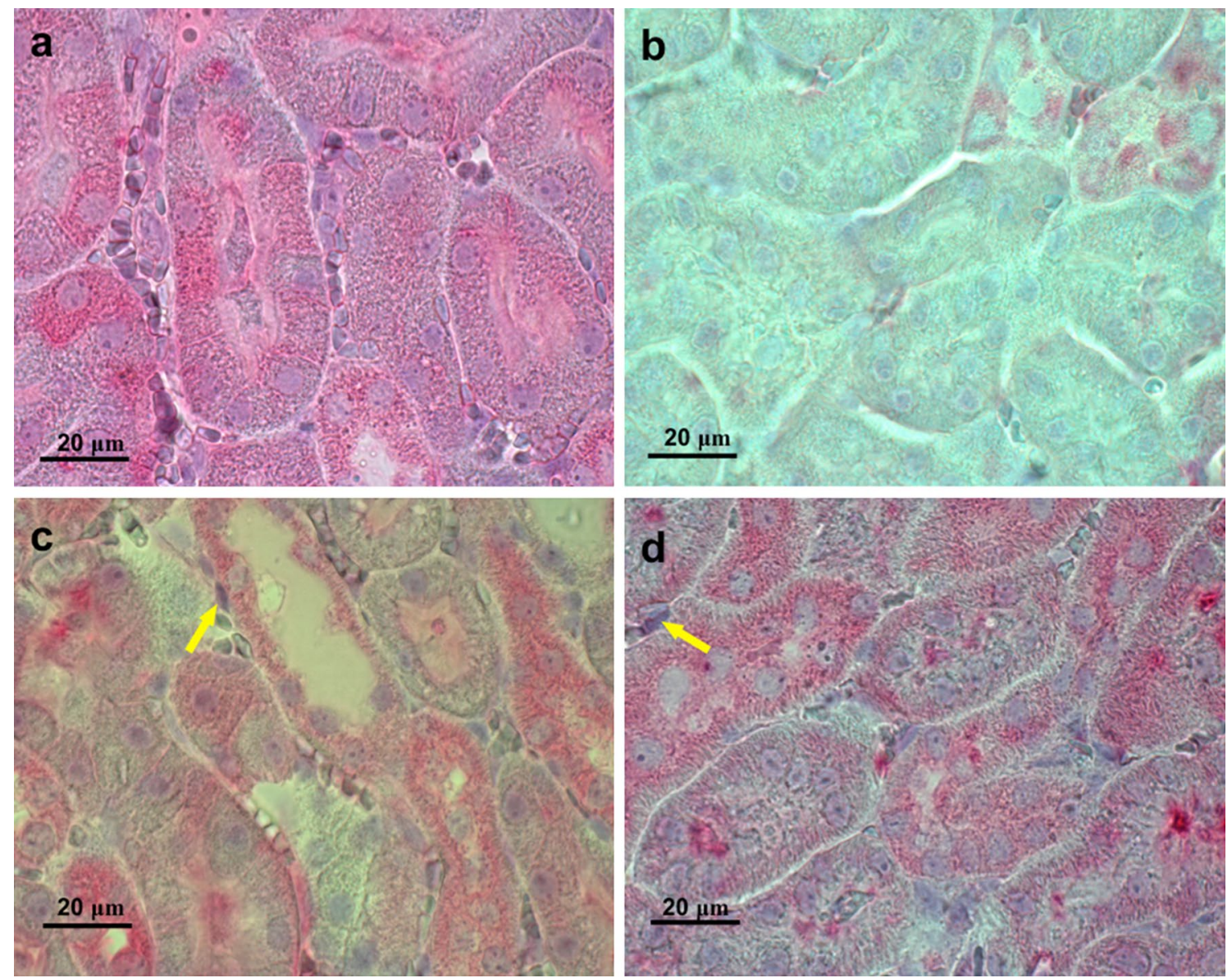

Fig. 8 Immunohistochemistry of NF-кB activation in the kidney by light microscopy. a Light micrograph from the control group showing only cytoplasmic staining without marked nuclear staining cells. b Light micrograph from polymyxin B group showing only cytoplasmic staining without marked nuclear staining cells. c Light micro-

in Fig. 9a, liver protein carbonylation increased significantly in $\alpha$-amanitin group (127.6 $\pm 7.1 \%)$ when compared to control group $(100.0 \pm 10.1 \%)$. Treatment with polymyxin B significantly attenuated hepatic $\alpha$-amanitin-induced increase in protein carbonylation $(107.8 \pm 16.1 \%)$. In the kidneys, although a tendency to increase was observed in the $\alpha$-amanitin group $(122.9 \pm 34.3 \%)$, when compared to control $(100.0 \pm 13.3 \%)$, no statistical significance was reached (Fig. 9b).

\section{Survival rate and welfare examination}

A long-term survival study (30 days) was done with two different polymyxin B treatment regimens after $\alpha$-amanitin $(0.33 \mathrm{mg} /$ $\mathrm{kg}$ i.p.): (1) Polymyxin $\mathrm{B}$ was administered at 4,8 , and $12 \mathrm{~h}$ $(3 \times 2.5 \mathrm{mg} / \mathrm{kg}$ i.p. $)$, and (2) polymyxin $\mathrm{B}(1 \times 2.5 \mathrm{mg} / \mathrm{kg})$ was concomitantly administered with $\alpha$-amanitin.

All mice exposed to $0.33 \mathrm{mg} / \mathrm{kg}$ of $\alpha$-amanitin died within 5 days (Fig. 10). All deaths occurred within 2-5 days $\alpha$-amanitin post-administration. graph from $\alpha$-amanitin group showing cell staining positive for activated NF-кB in the macrophage-like cells (yellow arrow). d Light micrograph from $\alpha$-amanitin plus polymyxin B group showing cell staining positive for activated $\mathrm{NF}-\kappa \mathrm{B}$ in the macrophage-like cells (yellow arrow) (color figure online)

$\alpha$-Amanitin-treated animals became hunched and lethargic soon after dosing. Subsequently, mice showed apathy, reduced mobility, respiratory problems, seizures, and disorientation until they died within $24 \mathrm{~h}$ of these symptoms arousal.

The concomitant administration of $\alpha$-amanitin and polymyxin B resulted in $100 \%$ of survival. The group that received concomitant administration of polymyxin B with $\alpha$-amanitin showed moderate signs of discomfort at day five, namely involuntary movements of the head that persisted without improvement until the end of the experiment.

In the group that received multiple doses of polymyxin $\mathrm{B}$ and $\alpha$-amanitin, a $50 \%$ survival rate was observed. All deaths occurred within 5-7 days. In the surviving animals that received multiple doses of polymyxin B and $\alpha$-amanitin, no poisoning signs were observed.

Neither the polymyxin B group $(3 \times 2.5 \mathrm{mg} / \mathrm{kg}$ i.p. $)$ nor the control group showed any other signs of discomfort during the 30-day experiment. 


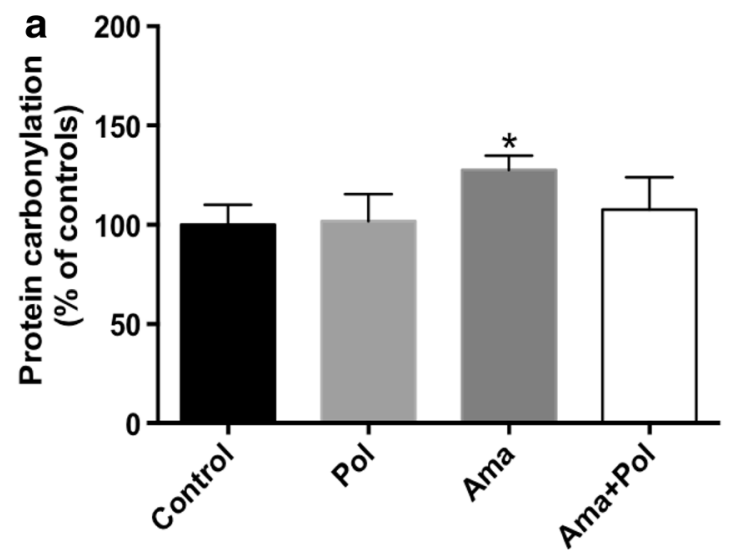

Fig. 9 a Protein carbonylation levels in the liver; $\mathbf{b}$ protein carbonylation levels in the kidney, control, $3 \times 2.5 \mathrm{mg} / \mathrm{kg}$ polymyxin $\mathrm{B}$ (Pol), $0.33 \mathrm{mg} / \mathrm{kg} \alpha$-amanitin (Ama), and $\alpha$-amanitin plus polymyxin $\mathrm{B}(\mathrm{Ama}+\mathrm{Pol})$ groups. Results were expressed as percentage variation of control values and expressed as mean \pm standard deviation.

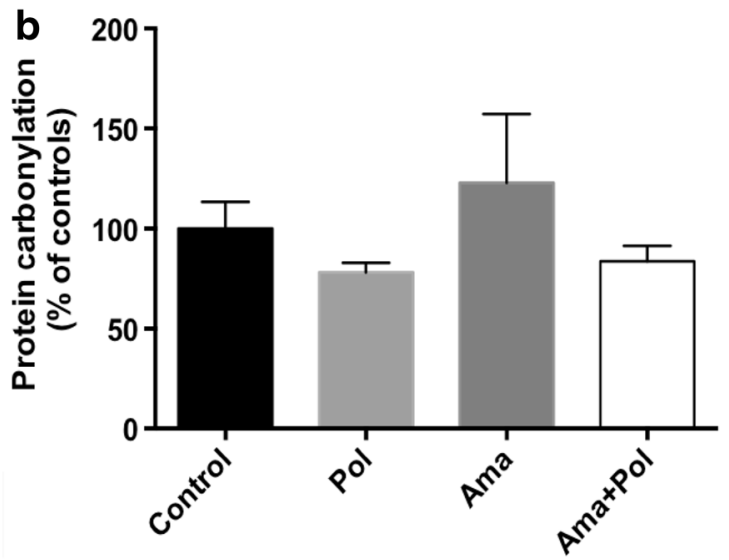

Results were obtained from four animals from each treatment group. Statistical comparisons were made by one-way ANOVA, followed by the Dunn's post hoc test, $\left({ }^{*} p<0.05\right.$, Ama vs. control; ${ }^{*} p<0.05$, Ama vs. Ama $+\mathrm{Pol})$

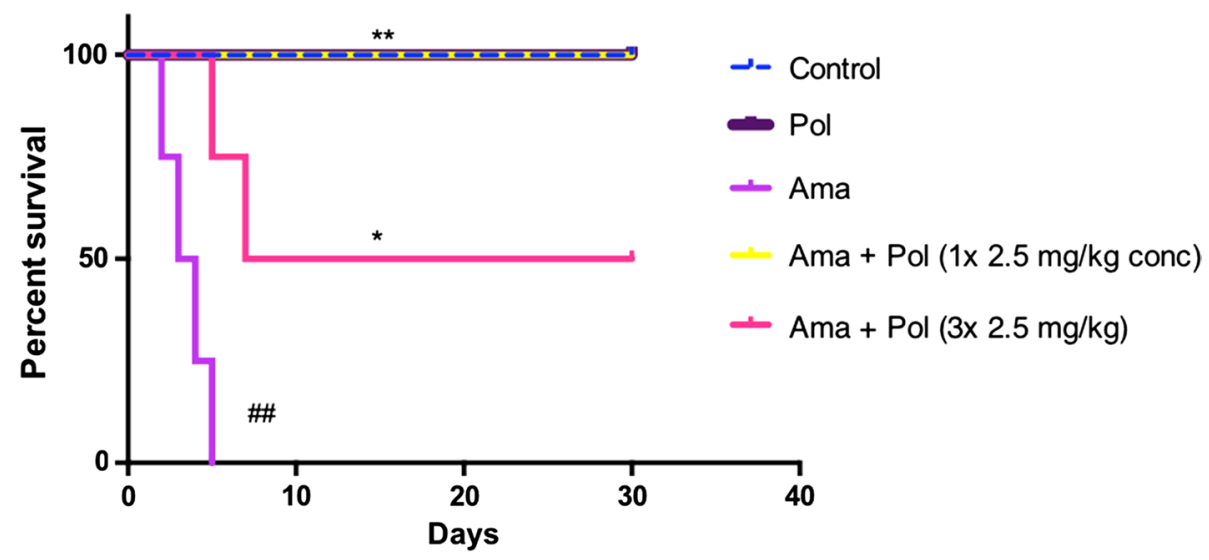

Fig. 10 Survival rate curves after concomitant i.p. administration of $0.33 \mathrm{mg} / \mathrm{kg}$ of $\alpha$-amanitin and polymyxin B $(2.5 \mathrm{mg} / \mathrm{kg})$ and administration of polymyxin B $(2.5 \mathrm{mg} / \mathrm{kg}) 4,8$, and $12 \mathrm{~h}$ after initial administration of $\alpha$-amanitin. Results are expressed as percent survival. Results were obtained from four animals in each treatment. Statistical comparisons were made using log-rank (Mantel-Cox) test $\left(^{*} p<0.05\right.$, Ama + Pol $2.5 \mathrm{mg} / \mathrm{kg}$ vs. Ama; ** $p<0.01$, Ama + Pol $2.5 \mathrm{mg} / \mathrm{kg}$ vs.

\section{Discussion}

The present work reports the discovery of what we believe will be the first effective antidote for A. phalloides poisoning: polymyxin $\mathrm{B}$. The present study provides unequivocal in silico and in vivo evidence that polymyxin B gives a potent protection against $\alpha$-amanitin-induced toxicity, by interfering with its main mechanism of toxicity, the inhibition of RNAP II activity. Outstandingly, the in silico studies on RNAP II were shown to be of outmost importance in the development process, and the successful in vivo studies allow the suggestion of immediate use of the antidote in
Ama; ${ }^{\#} p<0.01$, Ama vs. control). Blue line represents saline control treatment, dark purple represents polymyxin B treatment; violet line represents the treatment with $\alpha$-amanitin, yellow line represents the concomitant treatment with $\alpha$-amanitin and polymyxin B $(2.5 \mathrm{mg} /$ $\mathrm{kg}$ ), and magenta line represents the administration of polymyxin $\mathrm{B}$ $(3 \times 2.5 \mathrm{mg} / \mathrm{kg}) 4,8$, and $12 \mathrm{~h}$ after $\alpha$-amanitin (color figure online)

addition to the current therapeutic measures, as polymyxin $\mathrm{B}$ is a therapeutic drug with a well-established clinical use.

We started with the application of in silico methods, taking advantage of the description of the crystal structure of $\alpha$-amanitin with yeast RNAP II that revealed several key molecular interactions that may contribute to the inhibition of RNAP II activity (Bushnell et al. 2002). Based on that structure, we have recently reported an in silico study in which we provided new insights into the inhibition mechanism of RNAP II by $\alpha$-amanitin; additionally, the mode of interaction of $\alpha$-amanitin and three clinically used antidotes (benzylpenicillin, ceftazidime, and silybin) with 
RNAP II, using docking methods and molecular dynamics simulations, was investigated (Garcia et al. 2014). Multiple relevant interactions between $\alpha$-amanitin and RNAP II are located in the bridge helix and the trigger loop. Thus, $\alpha$-amanitin may block RNAP II translocation by interacting with the bridge helix, preventing the conformational change in the trigger loop and consequent transcriptional elongation. Benzylpenicillin, ceftazidime, and silybin were shown able to bind to the same site as $\alpha$-amanitin, although not replicating the unique $\alpha$-amanitin binding mode. These drugs establish considerably less intermolecular interactions than $\alpha$-amanitin, and the ones that exist are essentially confined to the bridge helix and adjacent residues (Garcia et al. 2014). These results show that the therapeutic effect of these drugs does not seem to be directly related to the binding with RNAP II but to other mechanisms. Therefore, an antidote that regenerates the RNAP II or that prevents the $\alpha$-amanitin binding to RNAP II does not yet exist and clinical efficacy of the treatments after A. phalloides is still low (Garcia et al. 2015a).

Herein, we have applied the same in silico methodology to a peptide with similar composition and molecular weight of amatoxins, polymyxin B, and confirmed its ability to displace $\alpha$-amanitin from RNAP II. Polymyxin B was never tested as an antidote for $\alpha$-amanitin. Docking and MD simulations were carried out to study the mode of interaction of RNAP II/polymyxin B complex using binding energy decomposition based on the MM-GBSA approach, as reported before for other molecules (Garcia et al. 2014). Three valuable findings could be observed in silico: (1) polymyxin B binding site is located in the same interface of $\alpha$-amanitin, which can prevent the binding of the toxin; (2) polymyxin B does not interact with bridge helix residues allowing the transcription process; and (3) hydrogen bond, $\mathrm{CH} / \pi$, and hydrophobic interactions drive the bonds between polymyxin B and RNAP II. Therefore, the polymyxin B binding location on RNAP II can potentially protect RNAP II from the $\alpha$-amanitin-induced impairment. In fact, competition between polymyxin $\mathrm{B}$ and $\alpha$-amanitin and/or displacement of $\alpha$-amanitin from RNAP II by polymyxin can occur depending on the affinity of each molecule for the RNAP II binding site.

To prove the applicability of our in silico results, we used an in vivo model often applied to study $\alpha$-amanitin toxicity (Schneider et al. 1987, 1992; Tong et al. 2007; Yamaura et al. 1986; Zhao et al. 2006). Since RNAP II is considered the main target for $\alpha$-amanitin toxicity, mRNA levels can be used as a measure of its inhibition (Larson 2011), and our results showed that inhibition of renal GAPDH and $\beta$-actin mRNA transcription elicited by $\alpha$-amanitin was efficiently reverted by polymyxin B. Still, in the liver, changes in mRNA levels of GAPDH and $\beta$-actin did not reach significance. This apparent discrepancy between the liver and kidney could be explained, at least partially, by the process of mRNA turnover. The turnover of mRNA is complex and organ/cell specific, and the several critical mechanisms are not yet fully understood (Beelman and Parker 1995; Guhaniyogi and Brewer 2001; Ross 1995). Moreover, the mRNA half-life varies greatly between different cell types. In rat hepatocytes, the half-life for $\beta$-actin mRNA is $9 \mathrm{~h}$ (Reuner et al. 1995), whereas in HepG2 cells it is reported as 5-6 h (Gao et al. 2003). In addition, a half-life of 6.6 and $13.5 \mathrm{~h}$ in human leukemia Nalm-6 (B cell derived) and CCRF-CEM (T cell derived) cells, respectively, was reported for the same mRNA transcript (Leclerc et al. 2002). Furthermore, the regulation of mRNA stability is likely to be an essential component in the tissue response to toxins exposure, and it differs among organs (Ross 1995). To the best of our knowledge, in CD-1 mice, the half-lives of hepatic or renal GAPDH and $\beta$-actin mRNA are not presently known. Moreover, in the present study, GAPDH seemed to be a more sensitive marker for $\alpha$-amanitin intoxication at $24 \mathrm{~h}$ in the kidney. However, organ differences of $\alpha$-amanitin accumulation may also have an important influence in the observed results, as we have previously reported (Garcia et al. 2015b).

Polymyxin B not only had a strong impact on genetic expression, but also caused a clear protection against $\alpha$-amanitin-induced injury. Serum aminotransferases (ALT and AST) have been used as sensitive indicators for liver injury caused by amatoxins (Chang and Yamaura 1993; Yamaura et al. 1986; Zhao et al. 2006) and, in accordance, in our model, AST and ALT were significantly increased in the $\alpha$-amanitin-intoxicated group. That $\alpha$-amanitin-induced increase was totally reverted by administration of multiple doses of $2.5 \mathrm{mg} / \mathrm{kg}$ polymyxin B. Moreover, the plasma findings were corroborated by histological observations. The liver of mice administered with $\alpha$-amanitin evidenced severe damage, with cellular edema, cytoplasmic vacuolization, and interstitial inflammatory cell infiltration, as well as some centrilobular necrotic zones. These histological phenotypes are in agreement with previous reports of $\alpha$-amanitin studies in mice (Kaya et al. 2014; Wills et al. 2005; Zhao et al. 2006). $\alpha$-Amanitin (1 mg/kg i.p.)-treated $\mathrm{Balb} / \mathrm{c}$ mice showed vacuolar degeneration of liver cells, 1 and $6 \mathrm{~h}$ after poisoning (Kaya et al. 2014), whereas $\alpha$-amanitin $(0.327 \mathrm{mg} / \mathrm{kg}$ intravenous $)$ caused liver fatty degeneration and necrosis $48 \mathrm{~h}$ after treatment in the same mice strain (Zhao et al. 2006). Moreover, histopathological hepatic damage in laboratory animals is similar to that found in humans after A. phalloides intoxication, namely regarding features of hepatic massive centrilobular necrosis and vacuolar degeneration (Fineschi et al. 1996).

Regarding the kidney, although less studied in humans, it is also a target organ for A. phalloides poisoning. Human 
data indicate that acute tubular necrosis with kidney failure occurs in amatoxins-intoxicated patients (Mydlik and Derzsiova 2006). In animal models, intense tubular necrosis was described in Balb/c mice $48 \mathrm{~h}$ after $\alpha$-amanitin (0.327 mg/kg intravenous) (Zhao et al. 2006). In our work, the histological examination of $\alpha$-amanitin-intoxicated kidney revealed extensive damage and a significant intratubular obstruction. Although the nature of that obstruction is unknown, the reduced tubular epithelial cell proliferation as a consequence of inhibition of RNAP II and cellular necrosis may lead to that material accumulation. Noteworthy, the administration of polymyxin B protected against the occurrence of the majority of the renal damage inflicted by $\alpha$-amanitin, namely cellular edema, cytoplasmic vacuolization, and necrosis. However, polymyxin B was not able to revert the hepatic and renal pro-inflammatory effect that occurred after $\alpha$-amanitin. Indeed, in the present work, NF- $\kappa \mathrm{B}$ was strongly activated in the liver and kidney exposed to $\alpha$-amanitin, whereas polymyxin was not able to revert that NF-кB nuclear translocation. The nuclear factor NF- $\kappa \mathrm{B}$ pathway has been considered a prototypical pro-inflammatory signaling pathway, based on the role of NF- $\mathrm{KB}$ in the expression of pro-inflammatory genes including cytokines, chemokines, and adhesion molecules (Lawrence 2009). To the best of our knowledge, this was the first time that NF-кB factor was shown to play a role on $\alpha$-amanitin toxicity. Moreover, NF- $\kappa B$ activation can promote liver injury through the genetic transcription of TNF- $\alpha$ and IL-6 (Murr et al. 2002; Zhang et al. 2007; Zhao et al. 2005). In fact, TNF- $\alpha$ has been implicated in $\alpha$-amanitin-induced hepatotoxicity in vivo, since after $\alpha$-amanitin ( $3 \mathrm{mg} / \mathrm{kg}$ i.p.), the levels of hepatic TNF messenger RNA were shown to increase, concurring to hepatocytes apoptosis (Leist et al. 1997). Consistently, mice deficient of the 55-kDa TNF receptor were protected from $\alpha$-amanitin-induced toxicity (Leist et al. 1997). The authors suggested that the synergism between TNF- $\alpha$ and $\alpha$-amanitin may explain the highly hepatotoxic potential of $\alpha$-amanitin in vivo (Leist et al. 1997). In the present work, it is reasonable to assume that the pro-inflammatory effect of NF-кB may be responsible for some of the late deaths on the survival study when polymyxin B was only administered $4 \mathrm{~h}$ after $\alpha$-amanitin. On the other hand, when administered concomitantly, polymyxin B possibly prevented $\alpha$-amanitin to reach RNAP II, thereby avoiding any significant side effect. The link between $\alpha$-amanitin RNAP II inhibition and NF- $\kappa \mathrm{B}$ activation should be further investigated as it could establish other pathways for antidotal therapy against this toxin.

$\alpha$-Amanitin toxicity has been associated with oxidative stress, and protein carbonylation is seen as a stable biomarker of oxidative stress as protein turnover can take hours or days (Dalle-Donne et al. 2003). Herein, protein carbonylation increased significantly in liver of mice exposed to $\alpha$-amanitin, relatively to the control group, suggesting that $\alpha$-amanitin is able to alter protein redox status. This effect was abrogated by the multiple administration of polymyxin B. Available data regarding $\alpha$-amanitin ability to induce oxidative stress are elusive. Mice treated with $\alpha$-amanitin $(1 \mathrm{mg} / \mathrm{kg}$ i.p.) and killed $20 \mathrm{~h}$ after poisoning showed liver superoxide dismutase activity increase (Zheleva et al. 2007). The authors concluded that in vivo $\alpha$-amanitin liver accumulation could lead to reactive oxygen species (ROS) formation, in particular superoxide anion radical (Zheleva et al. 2007). Recently, the levels of ROS in kidney homogenates isolated from $\alpha$-amanitin $(1 \mathrm{mg} / \mathrm{kg}$ i.p.)-treated mice were found to be increased (Zheleva 2013), whereas in vitro, the formation of phenoxyl radical after oxidation of $\alpha$-amanitin was demonstrated (Zheleva 2013). Although NF- $\kappa$ B pro-inflammatory activity is often associated with oxidative stress, in the present study, polymyxin B was able to abrogate $\alpha$-amanitininduced protein carbonylation and not NF- $\mathrm{KB}$ activation, suggesting that the mechanisms involved are dissimilar.

The hindrance of $\alpha$-amanitin overall toxicity by polymyxin B was established by a 30-day survival study. The administration of polymyxin $\mathrm{B}$ at 4,8 , and $12 \mathrm{~h}$ post$\alpha$-amanitin resulted in a $50 \%$ of survival rate, whereas all $\alpha$-amanitin-treated animals died within 5 days. In this experimental approach, polymyxin B was administered $4 \mathrm{~h}$ after $\alpha$-amanitin exposure, seeking a more realistic treatment approach, since hospitalization after $A$. phalloides human poisoning usually occurs only hours after ingestion. Importantly, the concomitant administration of polymyxin $\mathrm{B}$ and $\alpha$-amanitin resulted in $100 \%$ survival until the 30th day post-exposure, confirming the antidote efficacy.

Taken together, the in silico and the in vivo data obtained in the present study demonstrated that polymyxin B acts on RNAP II and prevents $\alpha$-amanitin toxicity. The use of polymyxin $\mathrm{B}$ in human mushroom poisonings will be the main goal to prove the validity of the present work. Clinical assays in intoxicated humans are feasible with polymyxin B since the doses used in this preclinical study are considered safe (Zavascki et al. 2007), when allometric scaling is applied. The three doses of $2.5 \mathrm{mg} / \mathrm{kg}$ of polymyxin B in mice sum up to approximately $1 \mathrm{mg} / \mathrm{kg}$ in humans, according to the allometric scaling (Beck et al. 2014). This polymyxin $B$ dose is below the recommended dose of intravenous polymyxin B for the treatment of infections caused by Pseudomonas aeruginosa in patients with normal renal function (Zavascki et al. 2007). The data presented herein suggest that polymyxin B may be used as a novel pharmacological approach to the treatment of A. phalloides poisoning. Thus, once its antidotal efficacy in humans is fully demonstrated, its rapid introduction in the therapeutic antidotal protocol will be of the outmost importance to increase 
the patient's survival rate of the putative fatal A. phalloides intoxication. For ethical reasons, however, polymyxin B should be added to the ongoing therapeutic protocol to improve A. phalloides survival and not replace it as to guarantee the maximal efficacy of the clinical pharmacological weapons available at this point.

Acknowledgments Juliana Garcia, Vera Marisa Costa, Ricardo Dinis-Oliveira and Ricardo Silvestre thank FCT-Foundation for Science and Technology-for their PhD grant (SFRH/ BD/74979/2010), Post-doc grants (SFRH/BPD/63746/2009 and SFRH/BPD/110001/2015) and Investigator grants (IF/01147/2013) and (IF/00021/2014), respectively. This work was supported by the Fundação para a Ciência e Tecnologia (FCT) - project PTDC/DTPFTO/4973/2014 - and the European Union (FEDER funds through COMPETE) and National Funds (FCT, Fundação para a Ciência e Tecnologia) through project Pest-C/EQB/LA0006/2013.

\section{Compliance with ethical standards}

Conflict of interest The authors declare that they have no conflict of interest.

\section{References}

Barbosa DJ, Capela JP, Oliveira JM et al (2012) Pro-oxidant effects of Ecstasy and its metabolites in mouse brain synaptosomes. Br J Pharmacol 165(4b):1017-1033

Beck BD, Seeley M, Calabrese EJ (2014) The use of toxicology in the regulatory process. In: Kruger CL (ed) Wallace H, A. Haye's principles and methods of toxicology. CRC Press, US, pp 35-87

Beelman CA, Parker R (1995) Degradation of mRNA in eukaryotes. Cell 81(2):179-183

Broussard CN, Aggarwal A, Lacey SR et al (2001) Mushroom poisoning-from diarrhea to liver transplantation. Am J Gastroenterol 96(11):3195-3198

Bushnell DA, Cramer P, Kornberg RD (2002) Structural basis of transcription: alpha-amanitin-RNA polymerase II cocrystal at $2.8 \mathrm{~A}$ resolution. Proc Natl Acad Sci USA 99(3):1218-1222

Case DA, Cheatham TE 3rd, Darden T et al (2005) The amber biomolecular simulation programs. J Comput Chem 26(16):1668-1688

Chang I-M, Yamaura Y (1993) Aucubin: a new antidote for poisonous amanita mushrooms. Phytother Res 7(1):53-56

Cheung PCK (2010) The nutritional and health benefits of mushrooms. Nutr Bull 35(4):292-299

Dalle-Donne I, Rossi R, Giustarini D, Milzani A, Colombo R (2003) Protein carbonyl groups as biomarkers of oxidative stress. Clin Chim Acta 329(1-2):23-38

Dores-Sousa JL, Duarte JA, Seabra V, Bastos Mde L, Carvalho F, Costa VM (2015) The age factor for mitoxantrone's cardiotoxicity: multiple doses render the adult mouse heart more susceptible to injury. Toxicology 329:106-119

Essmann U et al (1995) A smooth particle mesh Ewald method. J Chem Phys 103

Fineschi V, Di Paolo M, Centini F (1996) Histological criteria for diagnosis of amanita phalloides poisoning. J Forensic Sci 41(3):429-432

Gao C, Guo H, Downey L, Marroquin C, Wei J, Kuo PC (2003) Osteopontin-dependent CD44v6 expression and cell adhesion in HepG2 cells. Carcinogenesis 24(12):1871-1878

Garcia J, Carvalho AT, Dourado DF, Baptista P, de Lourdes Bastos M, Carvalho F (2014) New in silico insights into the inhibition of
RNAP II by alpha-amanitin and the protective effect mediated by effective antidotes. J Mol Graph Model 51:120-127

Garcia J, Costa V, Carvalho A et al (2015a) Amanita phalloides poisoning: mechanisms of toxicity and treatment (accepted)

Garcia J, Costa VM, Baptista P, Bastos MdL, Carvalho F (2015b) Quantification of alpha-amanitin in biological samples by HPLC using simultaneous UV- diode array and electrochemical detection. J Chromatogr B 997:85-95

Guhaniyogi J, Brewer G (2001) Regulation of mRNA stability in mammalian cells. Gene 265(1-2):11-23

He J, Gao S, Hu M, Chow DS, Tam VH (2013) A validated ultraperformance liquid chromatography-tandem mass spectrometry method for the quantification of polymyxin B in mouse serum and epithelial lining fluid: application to pharmacokinetic studies. J Antimicrob Chemother 68(5):1104-1110

Kaya E, Surmen MG, Yaykasli KO et al (2014) Dermal absorption and toxicity of alpha amanitin in mice. Cutan Ocul Toxicol 33(2): 154-160

Koda-Kimble MA, Alldredge BK, Corelli RL, Ernst ME (2012) Koda-Kimble and young's applied therapeutics: the clinical use of drugs. Wolters Kluwer Health/Lippincott Williams \& Wilkins, Baltimore

Kollman PA, Massova I, Reyes C et al (2000) Calculating structures and free energies of complex molecules: combining molecular mechanics and continuum models. Acc Chem Res 33(12):889-897

Larson DR (2011) What do expression dynamics tell us about the mechanism of transcription? Curr Opin Genet Dev 21(5):591-599

Lawrence T (2009) The nuclear factor NF- $\kappa$ B pathway in inflammation. Cold Spring Harb Perspect Biol 1(6):a001651

Leclerc G, Leclerc G, Barredo J (2002) Real-time RT-PCR analysis of mRNA decay: half-life of beta-actin mRNA in human leukemia CCRF-CEM and Nalm-6 cell lines. Cancer Cell Int 2(1):1

Leist M, Gantner F, Naumann H et al (1997) Tumor necrosis factorinduced apoptosis during the poisoning of mice with hepatotoxins. Gastroenterology 112(3):923-934

Morris GM, Huey R, Lindstrom W et al (2009) AutoDock4 and AutoDockTools4: automated docking with selective receptor flexibility. J Comput Chem 30(16):2785-2791

Mowry JB, Spyker DA, Cantilena LR Jr, Bailey JE, Ford M (2013) 2012 annual report of the american association of poison control centers' national poison data system (NPDS): 30th annual report. Clin Toxicol 51(10):949-1229

Murr MM, Yang J, Fier A, Kaylor P, Mastorides S, Norman JG (2002) Pancreatic elastase induces liver injury by activating cytokine production within kupffer cells via nuclear factor-kappa B. J Gastrointest Surg 6(3):474-480

Mydlik M, Derzsiova K (2006) Liver and kidney damage in acute poisonings. Bantao J 4(1):30-32

Onufriev A, Bashford D, Case DA (2000) Modification of the generalized born model suitable for macromolecules. J Phys Chem B 104(15):3712-3720

Pinson CW, Daya MR, Benner KG et al (1990) Liver transplantation for severe amanita phalloides mushroom poisoning. Am J Surg 159(5):493-499

Poucheret P, Fons F, Dore JC, Michelot D, Rapior S (2010) Amatoxin poisoning treatment decision-making: pharmaco-therapeutic clinical strategy assessment using multidimensional multivariate statistic analysis. Toxicon 55(7):1338-1345

Reuner KH, Wiederhold M, Dunker P et al (1995) Autoregulation of actin synthesis in hepatocytes by transcriptional and posttranscriptional mechanisms. Eur J Biochem 230(1):32-37

Ross J (1995) mRNA stability in mammalian cells. Microbiol Rev 59(3):423-450 
Schneider SM, Borochovitz D, Krenzelok EP (1987) Cimetidine protection against alpha-amanitin hepatotoxicity in mice: a potential model for the treatment of amanita phalloides poisoning. Ann Emerg Med 16(10):1136-1140

Schneider SM, Michelson EA, Vanscoy G (1992) Failure of N-acetylcysteine to reduce alpha amanitin toxicity. J Appl Toxicol 12(2):141-142

Tong TC, Hernandez M, Richardson WH 3rd et al (2007) Comparative treatment of alpha-amanitin poisoning with $\mathrm{N}$-acetylcysteine, benzylpenicillin, cimetidine, thioctic acid, and silybin in a murine model. Ann Emerg Med 50(3):282-288

Vetter J (1998) Toxins of amanita phalloides. Toxicon 36(1):13-24

Vogel G, Tuchweber B, Trost W, Mengs U (1984) Protection by silibinin against amanita phalloides intoxication in beagles. Toxicol Appl Pharmacol 73(3):355-362

Weiser J, Shenkin PS, Still WC (1999) Approximate atomic surfaces from linear combinations of pairwise overlaps (LCPO). J Comput Chem 20(2):217-230

Wieland T (1983) The toxic peptides from amanita mushrooms. Int J Pept Prot Res 22(3):257-276

Wieland T, Faulstich H (1978) Amatoxins, phallotoxins, phallolysin, and antamanide: the biologically active components of poisonous amanita mushrooms. CRC Crit Rev Biochem 5(3):185-260

Wills BK, Haller NA, Peter D, White LJ (2005) Use of amifostine, a novel cytoprotective, in alpha-amanitin poisoning. Clin Toxicol (Phila) 43(4):261-267
Yamaura Y, Fukuhara M, Takabatake E, Ito N, Hashimoto T (1986) Hepatotoxic action of a poisonous mushroom, amanita abrupta in mice and its toxic component. Toxicology 38(2):161-173

Zavascki AP, Goldani LZ, Li J, Nation RL (2007) Polymyxin B for the treatment of multidrug-resistant pathogens: a critical review. J Antimicrob Chemother 60(6): 1206-1215

Zhang XP, Zhang L, Chen LJ et al (2007) Influence of dexamethasone on inflammatory mediators and NF-kappaB expression in multiple organs of rats with severe acute pancreatitis. World J Gastroenterol 13(4):548-556

Zhao YF, Zhai WL, Zhang SJ, Chen XP (2005) Protection effect of triptolide to liver injury in rats with severe acute pancreatitis. Hepatobiliary Pancreat Dis Int 4(4):604-608

Zhao J, Cao M, Zhang J, Sun Q, Chen Q, Yang ZR (2006) Pathological effects of the mushroom toxin alpha-amanitin on BALB/c mice. Peptides 27(12):3047-3052

Zheleva A (2013) Phenoxyl radicals formation might contribute to severe toxicity of mushrooms toxin alpha-amanitin-an electron paramagnetic resonance study. TJS 11(1):33-38

Zheleva A, Tolekova A, Zhelev M, Uzunova V, Platikanova M, Gadzheva V (2007) Free radical reactions might contribute to severe alpha amanitin hepatotoxicity-a hypothesis. Med Hypotheses 69(2):361-367 